\title{
Adaptive CNC machining process optimization of near- net- shaped blade based on machining error data flow control
}

wU DONGBO

Iv hongru

Hui Wang ( $\square$ wdb4451253@126.com )

Tsinghua University

yu jie

\section{Research Article}

Keywords: Adaptive CNC machining process, Machining error data flow, Stiffness, Near- net- shaped blade

Posted Date: November 7th, 2022

DOI: https://doi.org/10.21203/rs.3.rs-664182/v3

License: (c) (i) This work is licensed under a Creative Commons Attribution 4.0 International License. Read Full License 


\title{
Adaptive CNC machining process optimization of near- net- shaped blade based on machining error data flow control
}

\author{
Dongbo $\mathrm{Wu}^{1,2}$, Hongru Lv ${ }^{1}$, Hui Wang ${ }^{1 *}$, Jie $\mathrm{Yu}^{3}$ \\ ${ }^{1}$ State Key Laboratory of Tribology, Beijing Key Lab of Precision/Ultra-Precision Manufacturing Equipment and \\ Control, Department of Mechanical Engineering, Tsinghua University, Beijing, China 100084, P.R. China. \\ ${ }^{2}$ Institute for Aero Engine, Tsinghua University, Beijing, China 100084, P.R. China. \\ ${ }^{3}$ AECC Xi'an Aero-engine LTD. Xi'an, Shannxi 710021, P. R. China. \\ \#Corresponding Author /E-mail: wanghuisx@gmail.com, TE, TEL: +86-10-62798599
}

\begin{abstract}
Adaptive $\mathrm{CNC}$ machining process is one of the efficient processing methods for near- net- shaped blade, this study proposes an adaptive $\mathrm{CNC}$ machining process optimization scheme based on multi-source and multi-process machining errors data flow control. The multi-process machining geometric error and mechanical models of the multi-process adaptive $\mathrm{CNC}$ machining process are firstly constructed. The machining error flow collaborative control of the near- net- shaped blade multi-process $\mathrm{CNC}$ machining is realized by the adaptive $\mathrm{CNC}$ machining process. The results show that the dynamic displacement response of the blade multi-process CNC machining process is controlled within $0.007 \mathrm{~mm}$. The optimized adaptive $\mathrm{CNC}$ machining process can realize the multi-process machining error control and high-precision manufacturing of near- net- shaped blade based on the multi- process geometric machining error data flow control and the sufficient stiffness of blade- fixture system. The process chain of the optimized adaptive $\mathrm{CNC}$ machining process based on machining error data flow control is reduced by $87 \%$ compared with the low melting point alloy pouring process, and 50\% compared with adaptive CNC machining process of the twice on-machine measurement on the blade body.
\end{abstract}

Keywords: Adaptive CNC machining process; Machining error data flow; Stiffness; Near- net- shaped blade. 


\section{Introduction}

Blade, as one of the most commonly used functional parts in aero-engine, is the key part for the realization and improvement of aero-engine performance due to their high mechanical performance requirements, high precision requirements and high surface quality requirements. The manufacture of blade which is a typical complex thin-walled curved is a challenge because of the extremely complex structure and precision requirements. The blade machining precise and efficient improvement is a key technology in contemporary advanced aero engine manufacturing [1].

Figure 1 is a typical near- net- shaped blade formed by the precision forging forming process, the contour error of the blade body is in the range of $0.008 \mathrm{~mm}$ to $0.05 \mathrm{~mm}$, which meets the accuracy requirements of the blade body and does not require subsequent $\mathrm{CNC}$ machining process. However, the subsequent CNC machining process of the blade leading and trailing edges (LTE), tenon root and tip is indispensable due to the small radius curvature and high precision requirement [2]. In the CNC machining process of the blade LTE, tenon root and tip, the only available positioning surface is the blade body profile. However, the formed blade body profile has an initial contour error of $0.008-0.05 \mathrm{~mm}$. The clamping surface is only the blade body which is a $5 \mathrm{~mm}$ thick blade. The high processing requirements which the contour error of the tenon root is less than $0.007 \mathrm{~mm}$, the roughness is less than Ra $0.8 \mathrm{um}$, and the section torsion is less than 0.15 degree should be finally completed by CNC machining process. Therefore, the machining error control and stiffness improvement are the key challenge for near- net- shaped blade CNC machining process.
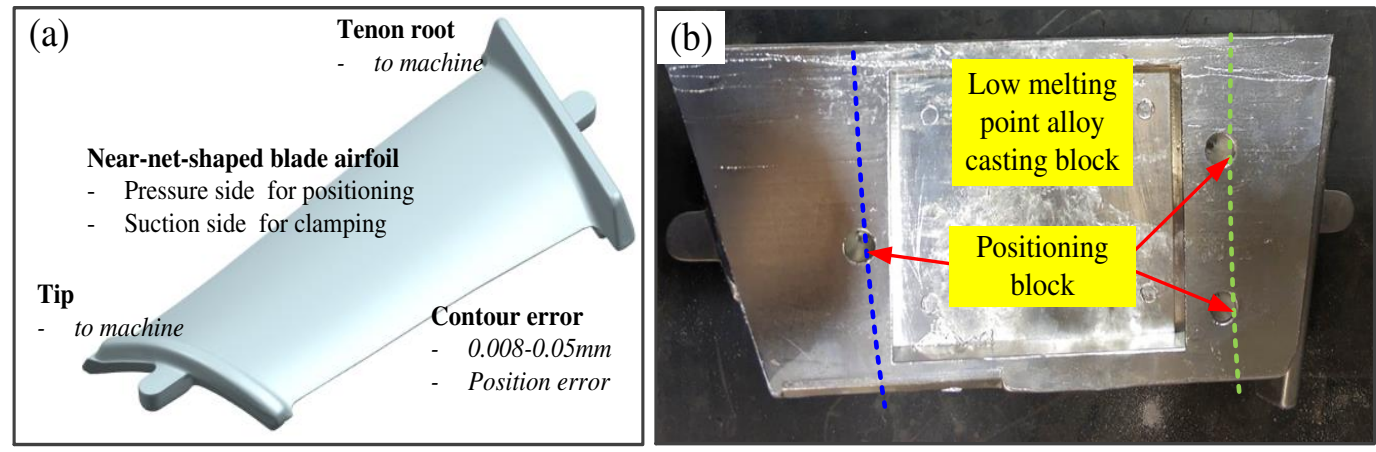

Fig. 1 Near- net- shaped blade and the low melting point alloy pouring process, (a) Near- net- shaped blade blank and (b) the low melting point alloy pouring process

The existing CNC machining process for this near- net- shaped blade is a lowmelting-point alloy casting method in which the blade is poured into a block through the low-melting-point alloy to improve the stiffness of the process system. There are 15 
process procedures in the mechanical processing stage (see Figure 2). However, disadvantages of the low surface positioning accuracy, long process chain, and blade surface alloy contamination make it is difficult to meet the performance requirements of the new generation aero-engine.

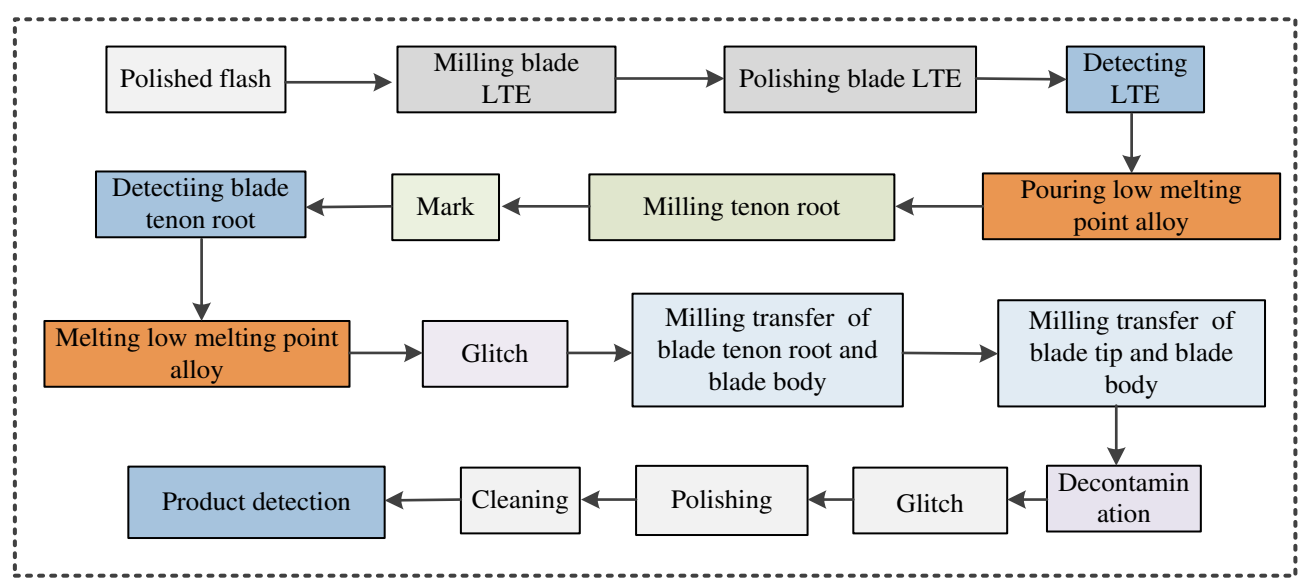

Fig. 2 The process flow of low melting point alloy pouring process

There are currently many studies for this type of blade CNC machining process which mainly focus on two aspects. One is the whole-process machining error control, and the other is the improvement of the rigidity of the process system.

The multi-source and multi-process machining error transmission is not conducive to the improvement of blade $\mathrm{CNC}$ machining accuracy because that various machining error features that affect the machining accuracy of blade curved parts are accumulated in space domain, and a variety of machining errors are transmitted in the time domain along with the blade multiple $\mathrm{CNC}$ machining process procedures. Therefore, the transmission control of the multi-source and multi-process machining errors are the key to improving the blade machining quality. SJ Hu et al. [3] proposed a theoretical method for the error flow of mechanical product assembly based on the error transmission characteristics of multiple parts. D. Ceglarek et al. [4, 5] further developed the statespace equation method to study assembly error variation relationship modeling, deviation transmission mechanism, and applied it to the quality modeling and process quality control of the multi-process assembly process of auto parts. Walid Ghiea et al. [6] proposed a tolerance zone representation theory based on Small Displacement Torsor (SDT), which represented a typical tolerance zone as a series of standardized numerical models, so as to perform error transfer calculations based on the Jacobian matrix. Rong et al. [7] comprehensively studied and explained the influence of positioning error on the accuracy of parts processing, and established a complete geometric positioning error calculation and sensitive factor analysis method. 
Mantripragada et al. [8] proposed a state transition model for the deviation transfer of a multi-process manufacturing system, which applies the control system theory to a multi-process manufacturing system.

The method of transmitting error data stream can be used to solve the error control problem of blade multi-process machining based on the above researches. Therefore, the use of machining error flow transfer method will be one of the main ways to optimize the $\mathrm{CNC}$ machining process of this type of blade.

There are also many researches on the enhancement of the rigidity of the blade machining process system. Jiayuan He et al. [9] used the finite element method (FEM) to study and optimize the fixture positioning layout to enhance the rigidity of thinwalled parts and reduce the deformation error in CNC machining processing. In fact, the first problem to be solved is to establish the stiffness analysis model of the bladefixture system. Considering the complexity of the blade- fixture system, the FEM has been widely used in recent years to obtain better results of part stiffness analysis. Asante et al. [10] studied the problem of elastic contact between fixture and workpiece, combining contact modeling and finite element methods to predict the load and pressure distribution in the contact area to determine the actual clamping force of the tangential and normal direction. Wang Ying et al. [11, 12] established a part stiffness analysis model by finite element method, and then discussed the correlation between positioning errors and machining errors, geometric errors and deformation errors, and the effect on the final machining accuracy of the blade surface basis on the contact analysis research between blade part and fixture. K.P. Padmanaban et al. [13] proposed a method to improve the layout of fixture through the Ant Colony Optimization algorithm to control the elastic deformation of parts. He Ning, et al. [14] paid more attention to the elastic deformation of parts under the cutting motion of the cutter during the machining process and the corresponding surface machining errors. Chen Weifang et al. [15] pointed out the importance of changing the fixture layout and clamping force to reduce the degree of freedom of part deformation and increase the consistency of surface deformation for controlling surface machining errors, and proposed a multi-objective optimization method based on genetic algorithm. E. Budak et al. [16] focused on the milling process of workpieces, and conducted more comprehensive research on cutting force, structural deformation and surface accuracy starting with cutting dynamics. Wu Baohai et al. [1719] analyzed the cutting force model and the dynamic characteristics of the blade and blisk, which contributed to the improvement of the performance of aero-engine blade. 
Guijian Xiao et al. [20] analyzed the vibration model during the abrasive belt polishing process, showing that the rigidity of the weak rigid system affects the machined surface

In summary, in order to achieve high-precision machining of near- net- shaped blade, the adaptive $\mathrm{CNC}$ machining process should be optimized from the stiffness improvement and machining error control. The structure of this study is arranged as follows. The multi-process adaptive $\mathrm{CNC}$ machining process of near- net- shaped blade is studied based on theoretical method in Section 2. The experimental conditions and methods for adaptive $\mathrm{CNC}$ machining process optimization and dynamic performance testing are shown in Section 3. Experimental results and discussion are in Section 4. The conclusion is summarized in section 5 .

\section{Theory of the multi-process adaptive $\mathrm{CNC}$ machining process}

As a machining method of near- net- shaped blade, the method of geometric adaptive CNC machining process is mainly based on the idea of closed-loop optimization iteration, online determination of the spatial pose and shape of the part, dynamic control of the processing plan and tool trajectory to improve blade machining accuracy.

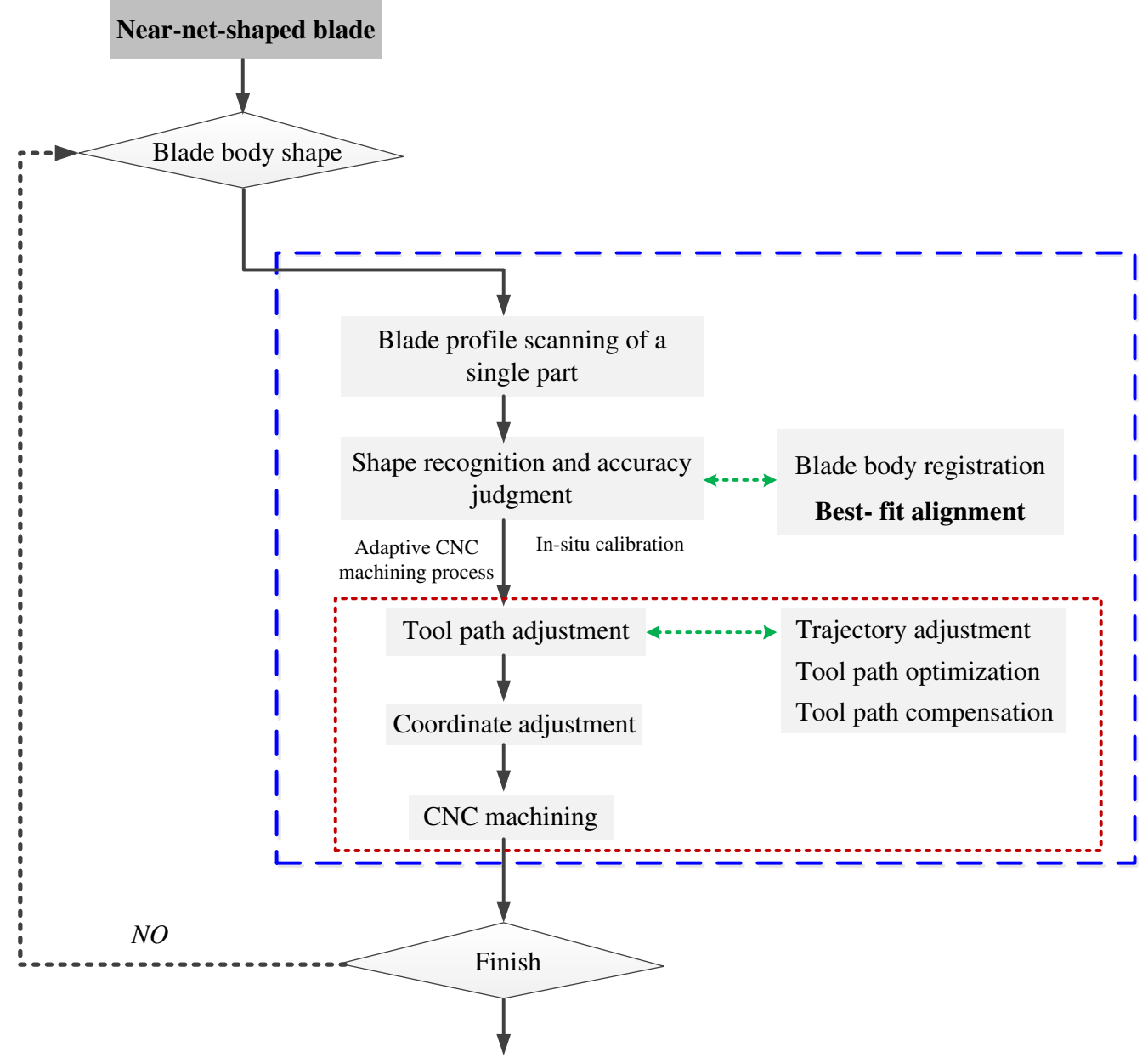


Fig. 3 The process flow of adaptive CNC machining process

Figure 3 is the process flow diagram of adaptive $\mathrm{CNC}$ machining process for nearnet- shaped blade. Firstly, it is essential to obtain the profile characteristics of each blade by scanning the blade profile based on on-machine measurement due to the contour accuracy of each near- net- shaped blade is inconsistent. Then the trajectory adjustment matrix is accurately calculated based on the measurement points and theoretical points. Finally, the tool position trajectory, coordinate adjustment or pose transformation are obtained to achieve high-performance CNC machining of near- net- shaped blade.

The spline curve is used to generate the blade body curve. In order to obtain the parametric equation of this spline curve, the curve control points need to be obtained.

$$
\mathbf{C}(u)=\frac{\sum_{i=0}^{n} N_{i, p}(u) \omega_{i} P_{i}}{\sum_{i=0}^{n} N_{i, p}(u) \omega_{i}}, a<u<b
$$

where $P_{i}$ is control point, $\omega_{i}$ is weight factor associated with the $P_{i}$, and $\omega_{i}>0, N_{i, p}(u)$ is a 3-order normative B-spline basis function defined on the non-uniform node

In order to obtain the parametric equation of this B-spline curve, the curve control points need to be obtained.

$$
U=\{\underbrace{0, \ldots, 0}_{p+1}, u_{p+1}, \ldots, u_{r-p-1}, 1, \ldots, 1\}
$$

When the control points of the blade section line are known, the one-element basis function is introduced.

$$
R_{i, p}(u)=\frac{N_{i, p}(u) \omega_{i}}{\sum_{j=0}^{n} N_{j, p}(u) \omega_{j}}
$$

The blade curve equation is generated:

$$
\mathbf{C}(u)=\sum_{i=0}^{n} R_{i, p}(u) P_{i}
$$

where $R_{i, p}(u)$ is the piecewise rational basis function defined on the interval $u \in[0,1]$.

In fact, if the measurement points in the actual state are obtained as the spline control points, the measurement model will be obtained according to Formula (1) to (4). The theoretical model corresponding to the measurement model can also be obtained. Therefore, what needs to be calculated in adaptive $\mathrm{CNC}$ machining process is the matrix relationship between the measurement points and the theoretical points, and can be 
obtained by the registration algorithm.

The registration principle is the least square method, and its essence is to obtain the minimum distance between the theoretical points and the measurement points, and to obtain the rotation and translation matrix based on this minimum distance.

$$
F=\min \sum_{i=1}^{n} d_{i}^{2}=\min \sum_{i=1}^{n}\left[\operatorname{distance}\left(p_{i}, q_{i}\right)\right]^{2}
$$

where $P_{i}$ is the measurement point, and $q_{i}$ is the theoretical point, $F$ is the target parameter of registration which is also the distance in this registration.

The rotation matrix is shown in Formula (6)

$$
R=\left[\begin{array}{ccc}
\cos \beta \cos \gamma & \cos \beta \sin \gamma & -\sin \beta \\
\sin \alpha \sin \beta \cos \gamma-\cos \alpha \sin \gamma & \sin \alpha \sin \beta \sin \gamma-\cos \alpha \cos \gamma & \sin \alpha \cos \beta \\
\cos \alpha \sin \beta \cos \gamma+\sin \alpha \cos \gamma & \cos \alpha \sin \beta \sin \gamma-\sin \alpha \cos \gamma & \cos \alpha \cos \beta
\end{array}\right]
$$

where $\alpha$ is the rotation angle of the blade along with the machine tool's $A$ axis, $\beta$ is the rotation angle of the blade along with the machine tool's $B$ axis, and $r$ is the rotation angle of the blade along with the machine tool's $C$ axis.

The translation matrix is shown in Formula (7)

$$
T=\left[\begin{array}{lll}
T_{x} & T_{y} & T_{z}
\end{array}\right]^{T}
$$

where, $T$ is the blade translation matrix, $T_{x}$ is the blade translation along with the machine tool's $x$ axis, $T_{y}$ is the blade translation along with the machine tool's $y$ axis, and $T_{z}$ is the blade translation along with machine tool's the $z$ axis.

The above Formulas of (1) to (7) are the geometric flow of the blade adaptive CNC machining process. The position and posture of the blade after clamping can be adjusted based on the above adaptive CNC machining process, and the blade deformation caused by the cutting force can also be adjusted based on the above adaptive CNC machining process. However, the blade deformation caused by the cutting force is a dynamic displacement response due to the cutting force is a dynamically changing time-varying force, and the real-time position and posture adjustment during the cutting process will break the continuity of cutting process, and the interrupt of the cutting process will cause the existence of tool marks, which will seriously affect the quality of blade. On the other hand, the real-time position and posture adjustment will also reduce the efficiency of blade CNC machining process. The dynamic response value of the blade during cutting processing is small if the stiffness of the blade process system is adequate, and the adaptive $\mathrm{CNC}$ machining process will have good efficiency and processing 
accuracy. Therefore, the sufficient stiffness of the blade process system and small dynamic displacement response are the prerequisite for the optimization of the adaptive CNC machining process.

In CNC machining process, the blade and fixture are the stiffness weak link in the process system relative to machine tools and cutter, and the blade- fixture system should have the sufficient capacity to suppress the blade deformation and vibration due to the blade is typical thin-walled part.

The blade deformation under the clamping force and cutting force is shown in Formula (8)

$$
\frac{\partial^{4} w}{\partial x^{4}}+2 \frac{\partial^{4} w}{\partial x^{2} \partial y^{2}}+\frac{\partial^{4} w}{\partial y^{4}}=\frac{1}{D}\left(p(x)+\sigma_{x} \frac{\partial^{2} w}{\partial x^{2}}+2 \tau_{x y} \frac{\partial^{2} w}{\partial x \partial y}+\sigma_{y} \frac{\partial^{2} w}{\partial y^{2}}\right)
$$

The dynamic equation of the blade- fixture system during the CNC machining process is shown in Formula (9).

$$
m \ddot{x}(t)+c \dot{x}(t)+k x(t)=f(t)+P \cos \omega_{0} t
$$

where $m$ is the modal mass, $c$ is the modal damping, $k$ is the modal stiffness, $f(t)$ is the self-excited force, and $P \cos \omega_{0} t$ is the harmonic force, where the frequency is $\omega_{0}$, and the amplitude is $P$, and $x(t)$ is the vibrational displacement between the cutter and the blade.

The forced vibration caused by the cyclic cutting force and the displacement response caused by the forced vibration will be copied on the blade surface, which will change the cutting depth of the blade, and this change cannot be adjusted by the adaptive CNC machining process. Therefore, the stiffness and damping of the blade- fixture system have a great influence on the dynamic behavior in the dynamic equation of the blade and is also a prerequisite for blade adaptive $\mathrm{CNC}$ machining process optimization.

\section{Conditions and methods}

The CNC machining process of near- net- shaped blade mainly includes three process procedures. The first process procedure is the CNC machining process of blade LTE. The second process procedure is the CNC machining process of blade tenon root and tip, and the third process procedure is the detection process of the contour error of the blade tenon root and the position error of blade tenon root which is relative to the blade body.

In order to achieve high precision CNC machining of near- net- shaped blade, the experiment is mainly considered from two aspects. One is to improve the stiffness of 
the blade- fixture system, and the other is to optimize the adaptive CNC machining process based on the multi- process machining error data flow control. The sufficient stiffness of blade system is the prerequisite guarantee for the subsequent adaptive $\mathrm{CNC}$ machining process optimization. The experiment method of the blade- fixture stiffness includes the natural frequency test of the blade- fixture system and the dynamic displacement response test of blade during the CNC machining process. The experiment of adaptive CNC machining process optimization includes the testing of machining errors in multiple- process of near- net- shaped blade. The experimental steps are as follows.

Step 1: Natural frequency test of the multi-process blade- fixture system. Figure 4 is the natural frequency test process of the first process sequence blade- fixture system. The acceleration sensor (Dytran 3225M23) is used to measure response curve of bladefixture system under the taping load of the hammer (Dytran 5850B). The LMS dataacquisition system is used to collect the displacement response signal of the bladefixture system from the acceleration sensor.

Figure 4 is the natural frequency test experiment platform of the first process procedure of near- net- shaped blade. The natural frequency of blade in the cantilever beam state is firstly tested (see Figure 4 (a)), and the natural frequency of blade in the simply supported beam state acted by machine tool top is then tested (see Figure 4 (b)). Finally, a reasonable clamping plan is obtained through comparative analysis to improve the stiffness of the blade- fixture system.
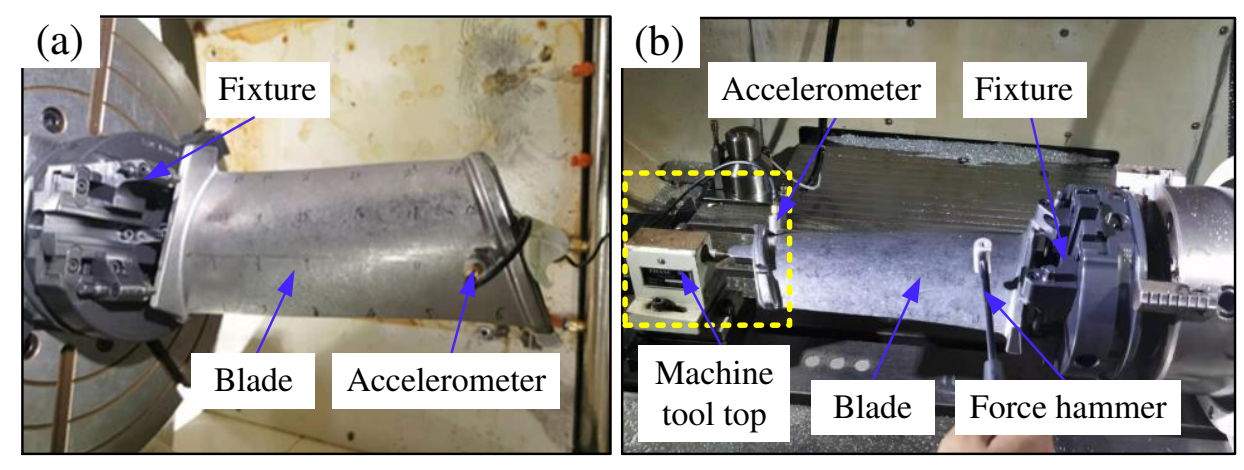

Fig. 4 Natural frequency test experiment platform of blade- fixture system in the first process sequence. (a) Blade in the cantilever beam state and (b) blade in the simply supported beam state

Figure 5 is the natural frequency test experiment platform of the second process procedure of near- net- shaped blade, fixture $1 \#$ is used as a comparative experiment, which was designed and manufactured according to traditional methods, and fixture $2 \#$ 
is obtained by our research team through fixture materials and structural layout optimization [21].
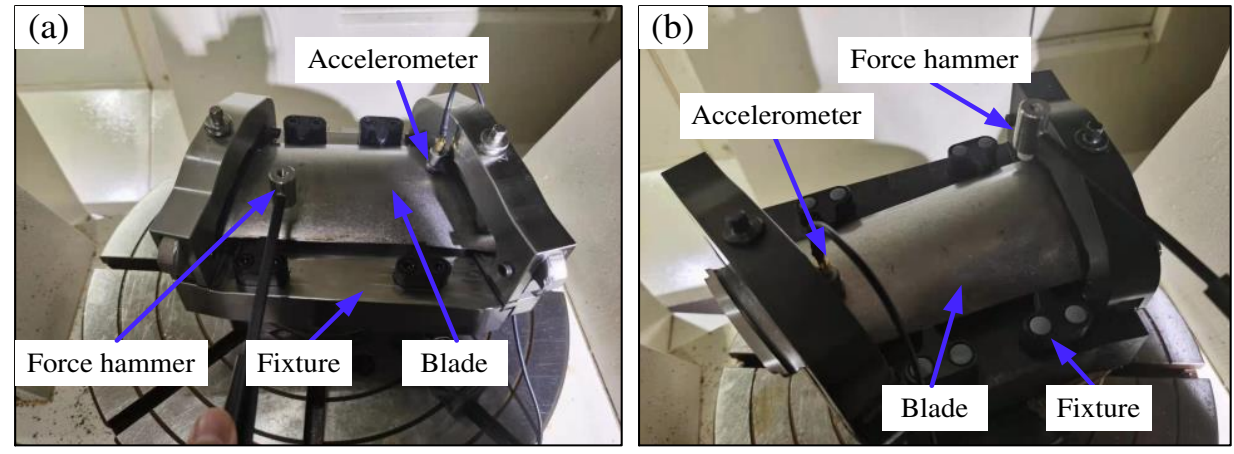

Fig. 5 Natural frequency test experiment platform of blade- fixture system in the second process sequence. (a) Fixture 1\# and (b) fixture 2\#

Step 2: Dynamic displacement response test of multi-process blade- fixture system. Figure 6 is the dynamic displacement response test experiment platform, and the laser displacement sensor is used to obtain the blade dynamic displacement response under the action of cutting force. The sensitivity of the laser displacement sensor is $0.001 \mathrm{~mm}$, and the measurement frequency is $1024 \mathrm{~Hz}$ to ensure that the blade dynamic displacement response under the dynamic cutting force is tracked. The acceleration sensor is used to measure the vibration characteristic of the blade- fixture system under the cutting force. The dynamic displacement response of the blade- fixture system can be obtained by frequency domain analysis and time domain analysis of the vibration signal obtained by the vibration acceleration sensor.
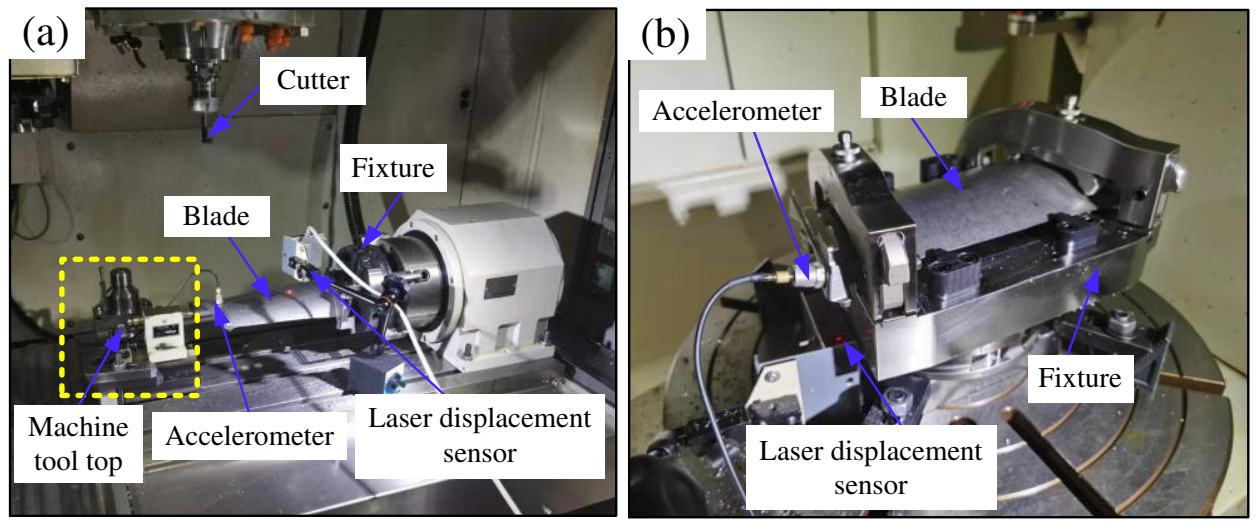

Fig. 6 Dynamic displacement response test experiment platform. (a)

The first process sequence and (b) the second process sequence

Step 3: Experimental test of multi-process adaptive CNC machining process optimization based on machining error data flow control. A four- axis and five-axis CNC machine tool with integrated Renishaw probe is used in this experiment, and the 
Renishaw probe is stored in the cutter magazine of machine tool, and the cutter and Renishaw probe can be switched in order by the cutter change system of machine tool.

\section{Results and discussion}

\subsection{Analysis of the natural frequency of the blade- fixture system}

Table 1 is the experiment result of the first order natural frequency of the blade- fixture system of the first process sequence. It can be seen that the first-order natural frequency of the blade- fixture system is $121.8 \mathrm{~Hz}$ in the cantilever beam state, and the first-order state damping ratio of the blade- fixture system is $0.3 \%$. The corresponding first-order mode shape is shown in Figure 7 (a). The first-order natural frequency of the bladefixture system is $400.1 \mathrm{~Hz}$ in the simply supported beam state which is under the constraint of the machine tool top, and the corresponding first-order damping ratio is $0.84 \%$. The corresponding first-order mode shape is shown in Figure 8 (a). Under the simply supported beam state, the stiffness and damping ratio of the blade-fixture system are increased by $228 \%$ and $180 \%$, respectively. The stiffness of the blade- fixture system under the constraint state of the machine tool top are greatly enhanced.

Table 1 Natural frequency of blade- fixture system under different constraints

\begin{tabular}{llclr}
\hline \multirow{2}{*}{ Number } & \multicolumn{2}{l}{$\begin{array}{l}\text { Constraint status 1\# } \\
\text { In the cantilever beam state } \\
\end{array}$} & $\begin{array}{l}\text { Constraint status 2\# } \\
\text { Without machine tool top }\end{array}$ & $\begin{array}{l}\text { In the simply supported beam state } \\
\text { With machine tool top }\end{array}$ \\
\cline { 2 - 5 } & Frequency (Hz) & Damping (\%) & Frequency (Hz) & Damping (\%) \\
\hline 1 & $121.8 \mathrm{~Hz}$ & $0.3 \%$ & $400.1 \mathrm{~Hz}$ & $0.84 \%$ \\
2 & $354.1 \mathrm{~Hz}$ & $0.73 \%$ & $537.6 \mathrm{~Hz}$ & $0.96 \%$ \\
3 & $435 \mathrm{~Hz}$ & $2.8 \%$ & $1222.6 \mathrm{~Hz}$ & $1.86 \%$ \\
4 & $825.7 \mathrm{~Hz}$ & $0.62 \%$ & $1372.8 \mathrm{~Hz}$ & $1.4 \%$ \\
5 & $1323.6 \mathrm{~Hz}$ & $0.52 \%$ & $2295.1 \mathrm{~Hz}$ & $1.18 \%$ \\
\hline
\end{tabular}

The second-order natural frequency of the blade- fixture system is $354.1 \mathrm{~Hz}$ in the cantilever beam state, and the second-order state damping ratio of the blade- fixture system is $0.73 \%$. The corresponding second-order mode shape is shown in Figure 7 (b). The second-order natural frequency of the blade- fixture system is $537.6 \mathrm{~Hz}$ in the simply supported beam state which is under the constraint of the machine tool top, and the corresponding second-order damping ratio is $0.96 \%$. The corresponding second- 
order mode shape is shown in Figure 8 (b). The stiffness of the blade- fixture system is increased by $51.8 \%$, and the damping ratio is increased by $31.5 \%$ under the simply supported beam state. The stiffness of the blade- fixture system under the constraint state of the machine tool top are greatly enhanced.
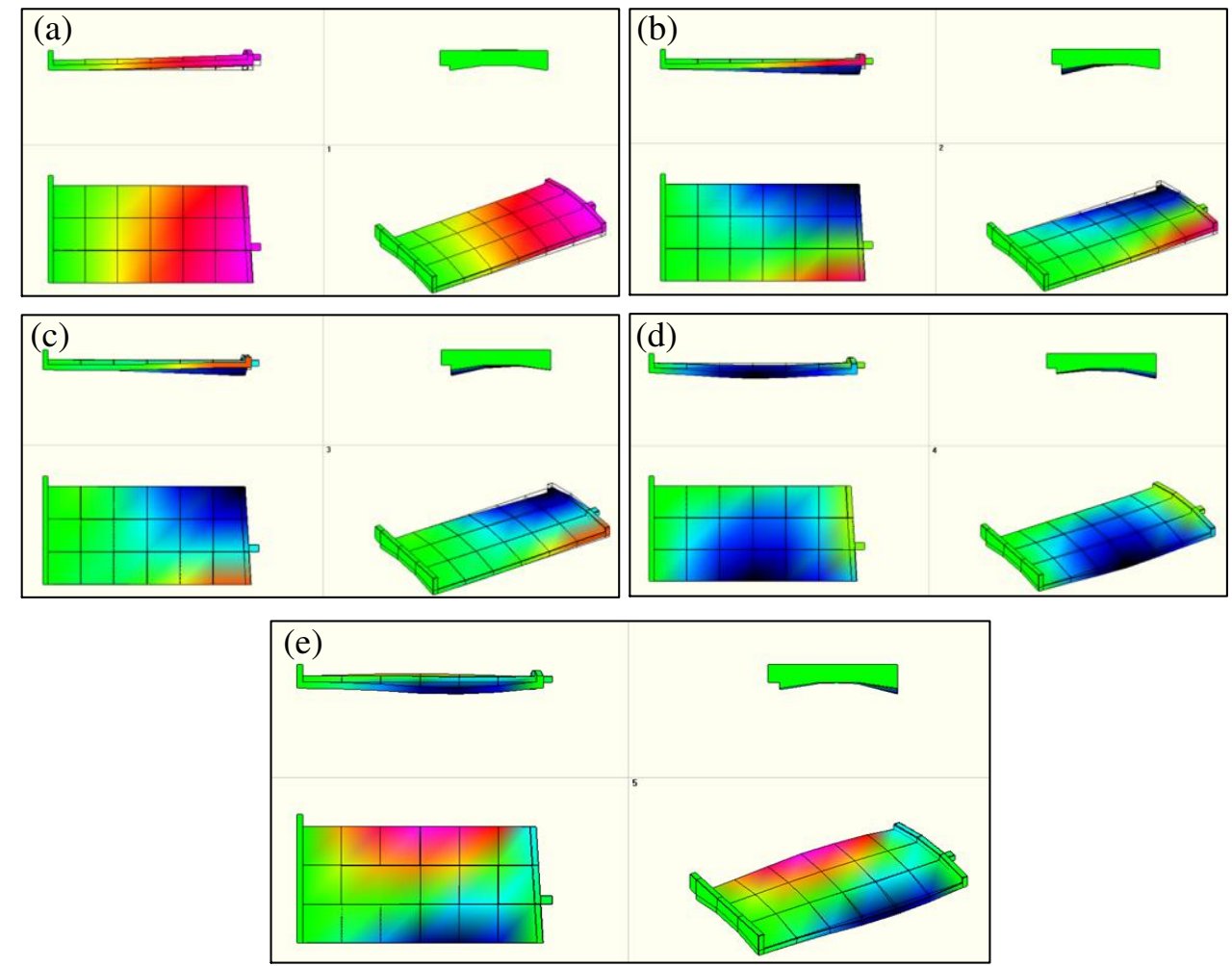

Fig. 7 The mode shape of blade- fixture system of the first process sequence in the cantilever beam state without machine tool top. (a) The first-order mode shape, (b) the second-order mode shape, (c) the third-order mode shape, (d) the fourth-order mode shape and (e) the fifth-order mode shape

Similarly, it can be seen that the third-order natural frequency of the blade- fixture system is increased by $181 \%$ and the damping ratio is reduced by $33 \%$ under the constraint state of the machine tool top. The fourth-order natural frequency of the bladefixture system under the constraint state of the machine tool top is increased by $66 \%$, and the damping ratio is increased by $125 \%$. The fifth-order natural frequency of the system under the constraint state of the machine tool top is increased by $73 \%$, and the damping ratio is increased by $126 \%$. Therefore, the stiffness of the blade- fixture system in the first processing procedure is greatly enhanced under the constraints of the machine tool top, which obtain a good dynamic characteristic. 

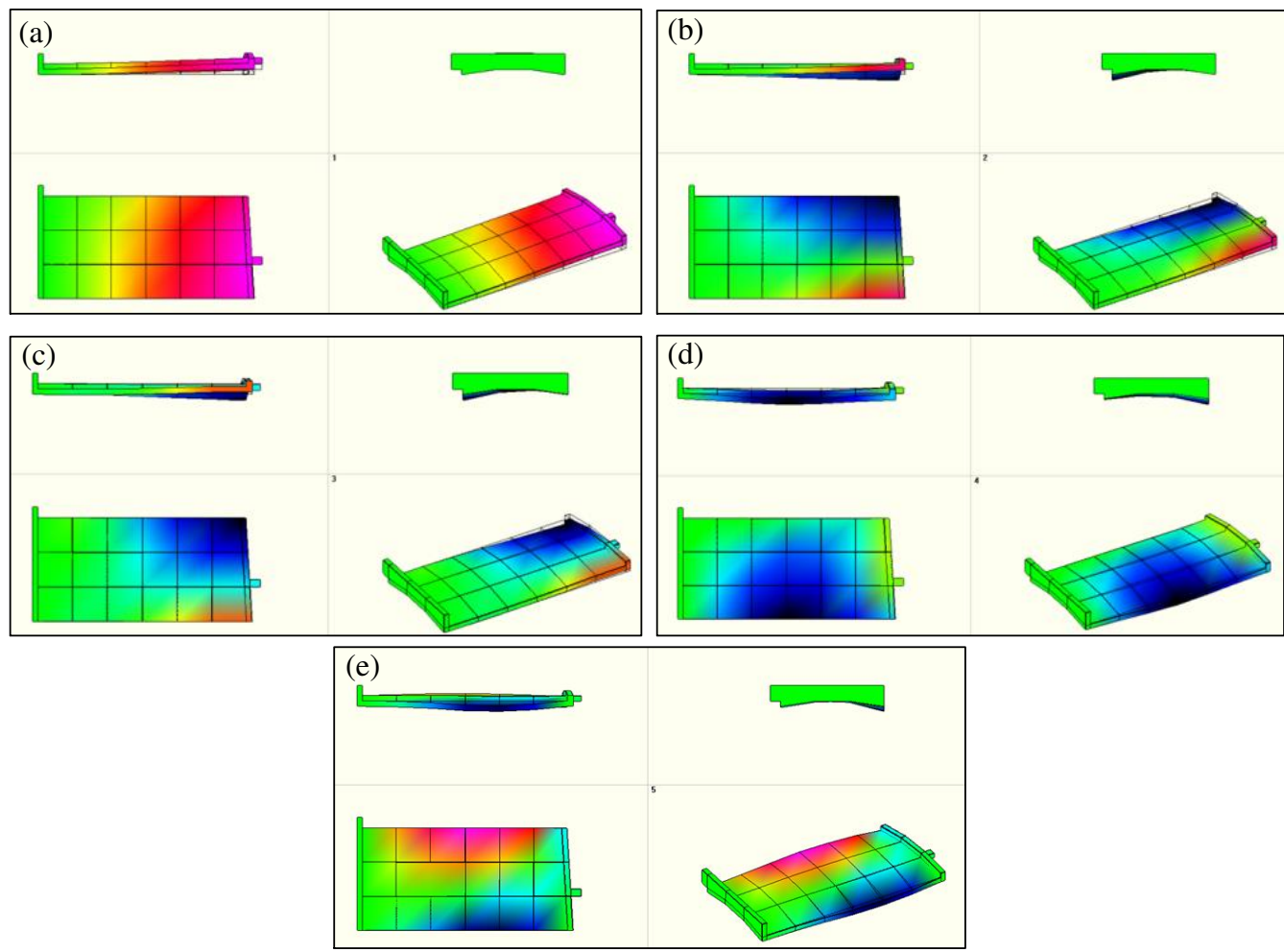

Fig. 8 The mode shape of blade- fixture system of the first process sequence in the simply supported beam state with machine tool top.

(a) The first-order mode shape, (b) the second-order mode shape, (c) the third-order mode shape, (d) the fourth-order mode shape and (e) the fifth-order mode shape.

Table 2 is the experiment result of the natural frequency of the blade- fixture system of the second processing procedure. It can be seen that the first-order natural frequency of the blade- fixture $1 \#$ system is $1105.5 \mathrm{~Hz}$, and the first-order damping ratio of the blade- fixture1\# system is $1.78 \%$. The corresponding mode shape is shown in Figure 9 (a). The first-order natural frequency of the blade- fixture 2\# system is 1040.7 $\mathrm{Hz}$, and the first-order damping ratio of the blade- fixture $2 \#$ system is $1.97 \%$. The corresponding mode shape is shown in Figure 10 (a). The first-order natural frequency of the blade- fixture $2 \#$ system is increased by $5 \%$, and the first-order damping ratio is reduced by $8 \%$ relative to the blade- fixture $1 \#$ system.

Table 2 Natural frequency of blade- fixture system of the second processing procedure

\begin{tabular}{lcccc}
\hline \multirow{2}{*}{ Number } & \multicolumn{2}{c}{ Fixture 1\# } & \multicolumn{2}{c}{ Fixture 2\# } \\
\cline { 2 - 5 } & Frequency (Hz) & Damping (\%) & Frequency (Hz) & Damping (\%) \\
\hline 1 & $1105.5 \mathrm{~Hz}$ & $1.78 \%$ & $1040.7 \mathrm{H}$ & $1.94 \%$
\end{tabular}




\begin{tabular}{ccccc}
2 & $1704.8 \mathrm{~Hz}$ & $0.475 \%$ & $1684 \mathrm{~Hz}$ & $1.15 \%$ \\
3 & $2385.3 \mathrm{~Hz}$ & $1.4 \%$ & $2384.9 \mathrm{~Hz}$ & $1.664 \%$ \\
\hline
\end{tabular}

It can be seen that the first-order natural frequency of the blade- fixture1\# system is $1105.5 \mathrm{~Hz}$, and the first-order damping ratio of the blade- fixture1\# system is $1.78 \%$. The corresponding mode shape is shown in Figure 10 (a). The first-order natural frequency of the blade- fixture $2 \#$ system is $1040.7 \mathrm{~Hz}$, and the first-order damping ratio of the blade- fixture $2 \#$ system is $1.97 \%$. The corresponding mode shape is shown in Figure 10 (a). The first-order natural frequency of the blade- fixture 2\# system is increased by $5 \%$, and the first-order damping ratio is reduced by $8 \%$ relative to the blade- fixture 1 \# system.

Similarly, it can be seen that the second -order natural frequency of the bladefixture system $2 \#$ is increased by $1 \%$, and the second -order damping ratio is increases by $13 \%$ relative to the blade- fixture $1 \#$ system. The third -order natural frequency of the blade- fixture system $2 \#$ is increased by $0.1 \%$, and the third -order damping ratio is increases by $18 \%$ relative to the blade- fixture $1 \#$ system. Therefore, the stiffness of the blade- fixture $1 \#$ system in the second process procedure has the good dynamic characteristics than the blade- fixture $2 \#$ system. 

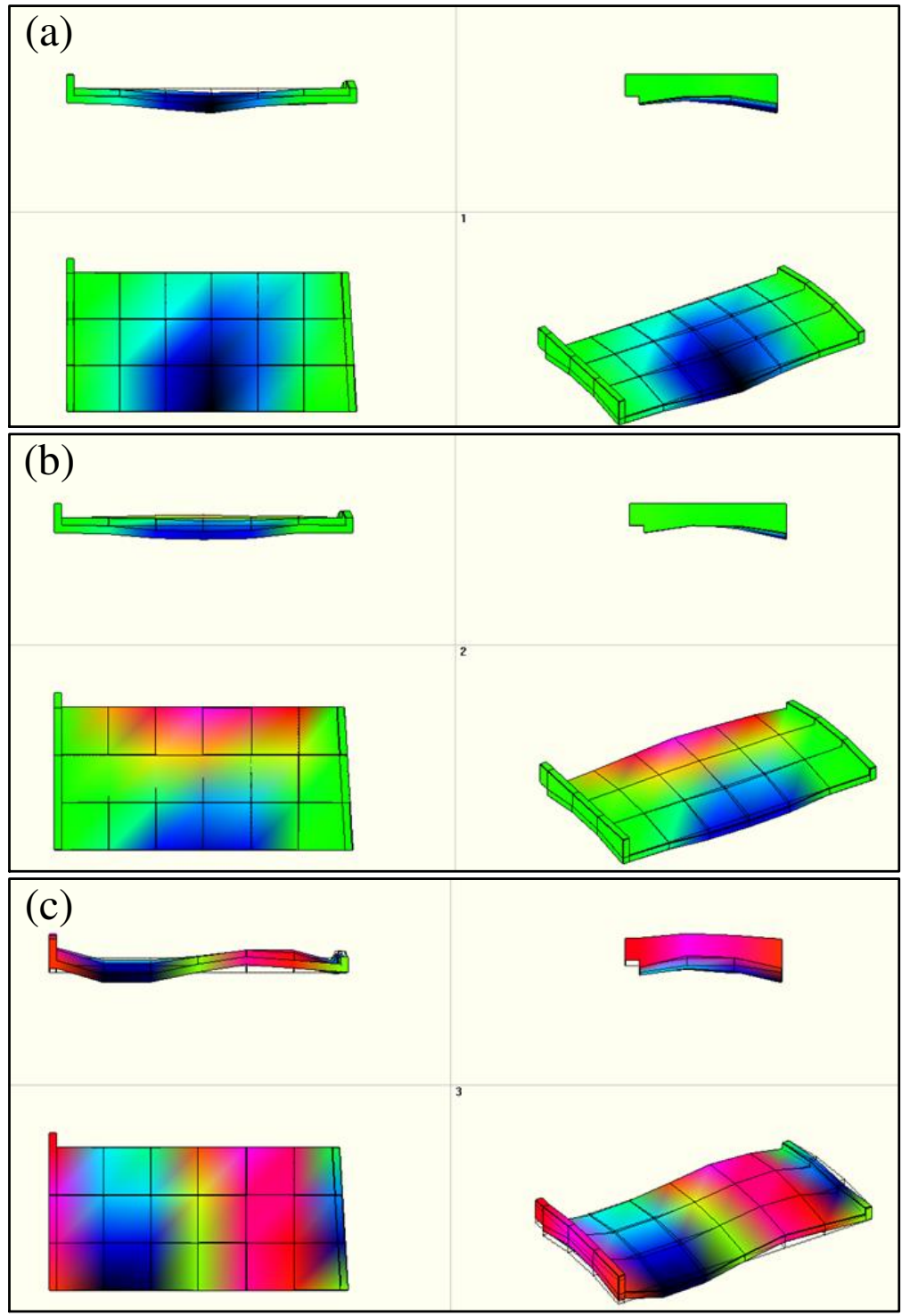

Fig. 9 Mode shape of blade- fixture 1\# system of the second process sequence. (a) The first-order mode shape, (b) the second-order mode shape and (c) the third-order mode shape 

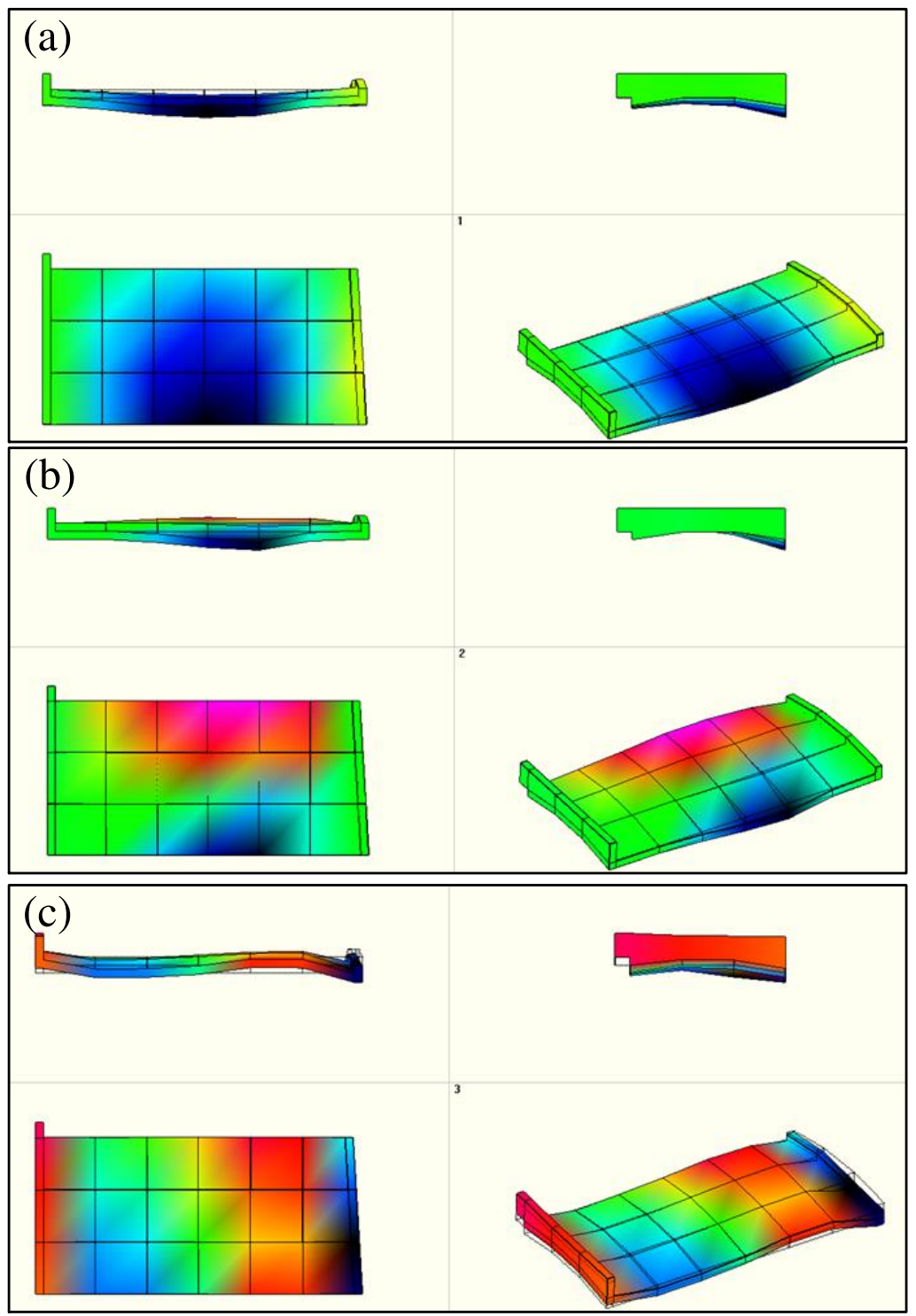

Fig. 10 Mode shape of blade- fixture 2\# system of the second process sequence. (a) The first-order mode shape, (b) the second-order mode shape and (c) the third-order mode shape

\subsection{Analysis of dynamic displacement response of blade- fixture system}

Figure 11 is the dynamic displacement response experimental result during blade CNC machining process. Figure $11(\mathrm{a})$ is the vibration value obtained by vibration acceleration. Figure 11(b) is the vibration value during a cycle of cutter force. Figure 11(c) is the blade dynamic displacement response obtained by the high-precision, highresolution laser displacement sensor, and Figure 11(d) is the low-frequency change of the dynamic displacement response fitted by a low-pass filter. 

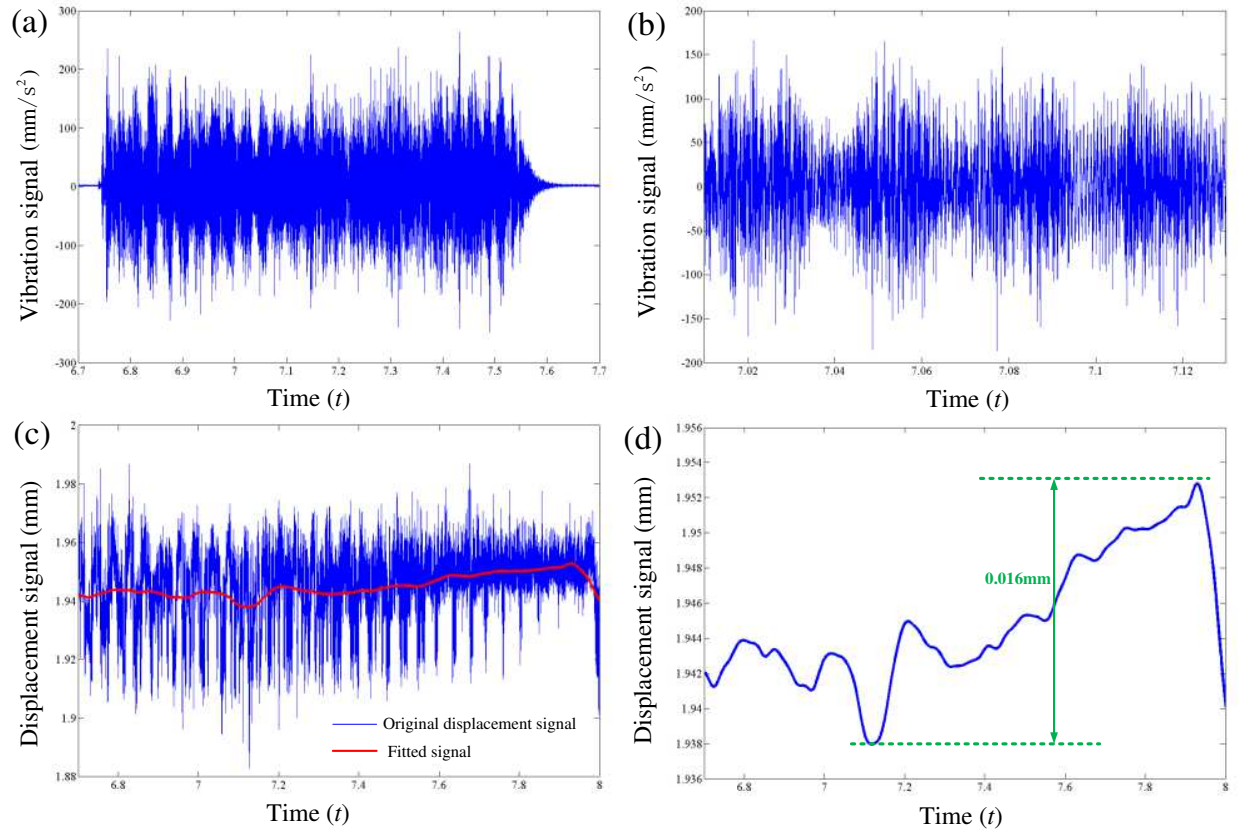

Fig. 11 Dynamic displacement response of blade-fixture system in the first process sequence (with the machine tool top). (a) Blade vibration during $\mathrm{CNC}$ machining process, (b) vibration value during a cycle of cutter force, (c) blade dynamic displacement response and (d) lowfrequency dynamic displacement response of blade

It can be seen from Figure 11 and Figure 12 that the existence of the machine tool top greatly improves the stiffness of the blade- fixture system, and the max dynamic displacement response value of the blade is reduced by $1 / 5$ under the same process parameters. The max dynamic displacement response value under suitable process parameters is less than $0.007 \mathrm{~mm}$ (see Figure 13 and Table 3) which is the instantaneous displacement change of the blade- fixture system and essentially the elastic deformation of the blade- fixture system under the cutting force. It can be concluded that the bladefixture system has sufficient stiffness in the first process sequence. 

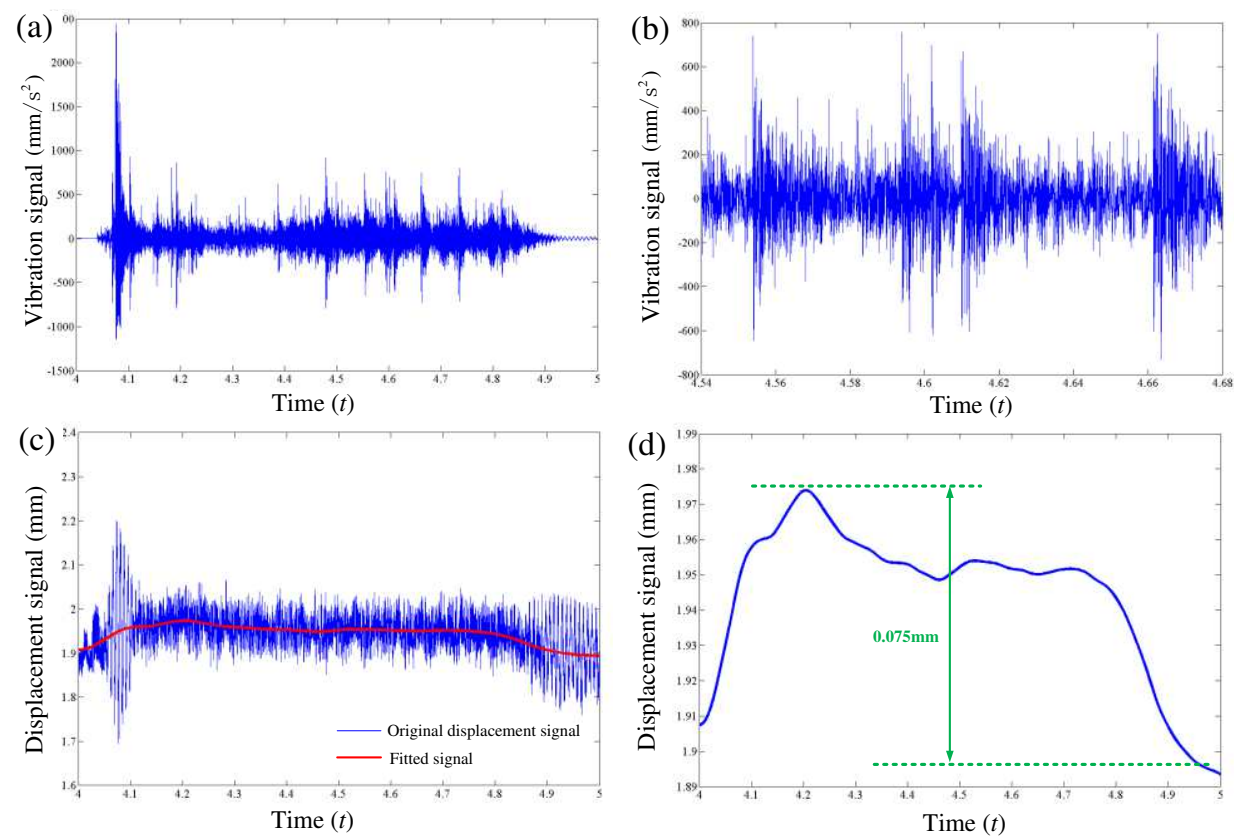

Fig. 12 Dynamic displacement response of blade-fixture system in the first process sequence (without the machine tool top). (a) Blade vibration during $\mathrm{CNC}$ machining process, (b) vibration value during a cycle of cutter force, (c) blade dynamic displacement response and (d) low-frequency dynamic displacement response of blade

Table 3 The processing parameters and the max dynamic displacement value of the first process sequence in simply supported beam state with the machine tool top

\begin{tabular}{crrrc}
\hline Number & $\begin{array}{l}\text { Spindle } \\
\text { speed }(\mathrm{rpm})\end{array}$ & $\begin{array}{c}\text { Feed rate } \\
(\mathrm{mm} / \mathrm{min})\end{array}$ & $\begin{array}{c}\text { Cutting } \\
\text { depth }(\mathrm{mm})\end{array}$ & $\begin{array}{c}\text { The max value of } \\
\text { dynamic displacement } \\
\text { response }(\mathrm{mm})\end{array}$ \\
\hline 1 & 2000 & 1200 & 0.2 & 0.016 \\
2 & 3000 & 800 & 0.2 & 0.017 \\
3 & 3000 & 1000 & 0.2 & 0.007 \\
4 & 3000 & 1200 & 0.1 & 0.021 \\
5 & 3000 & 1200 & 0.2 & 0.011 \\
6 & 3000 & 1200 & 0.3 & 0.017 \\
7 & 3000 & 1200 & 0.05 & 0.007 \\
8 & 3000 & 1400 & 0.2 & 0.038 \\
9 & 4000 & 1200 & 0.2 & 0.023
\end{tabular}




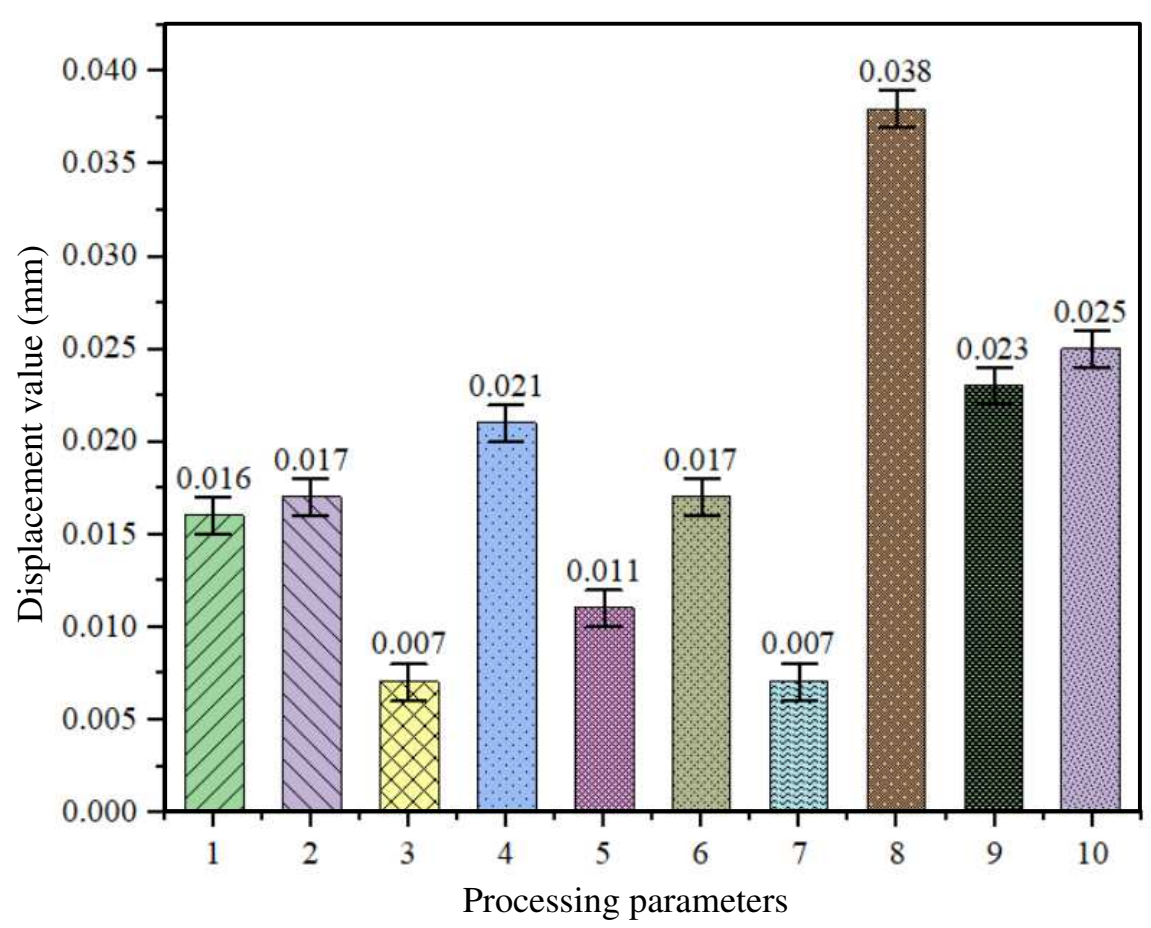

Fig. 13 The processing parameters and the max dynamic displacement value of the first process sequence in simply supported beam state with the machine tool top

Figure 14 and Figure 15 is the dynamic displacement response experimental result during the second process sequence. It can be seen that the proposed fixture (fixture 1\#) is of good dynamic characteristics to resist cutting force. The max dynamic displacement change value of the corresponding blade- fixture system under suitable process parameters can be controlled within $0.007 \mathrm{~mm}$, and the max dynamic displacement change value under different process parameters can still be controlled within $0.014 \mathrm{~mm}$, which indicates that the blade- fixture system has sufficient stiffness in the second process sequence. 

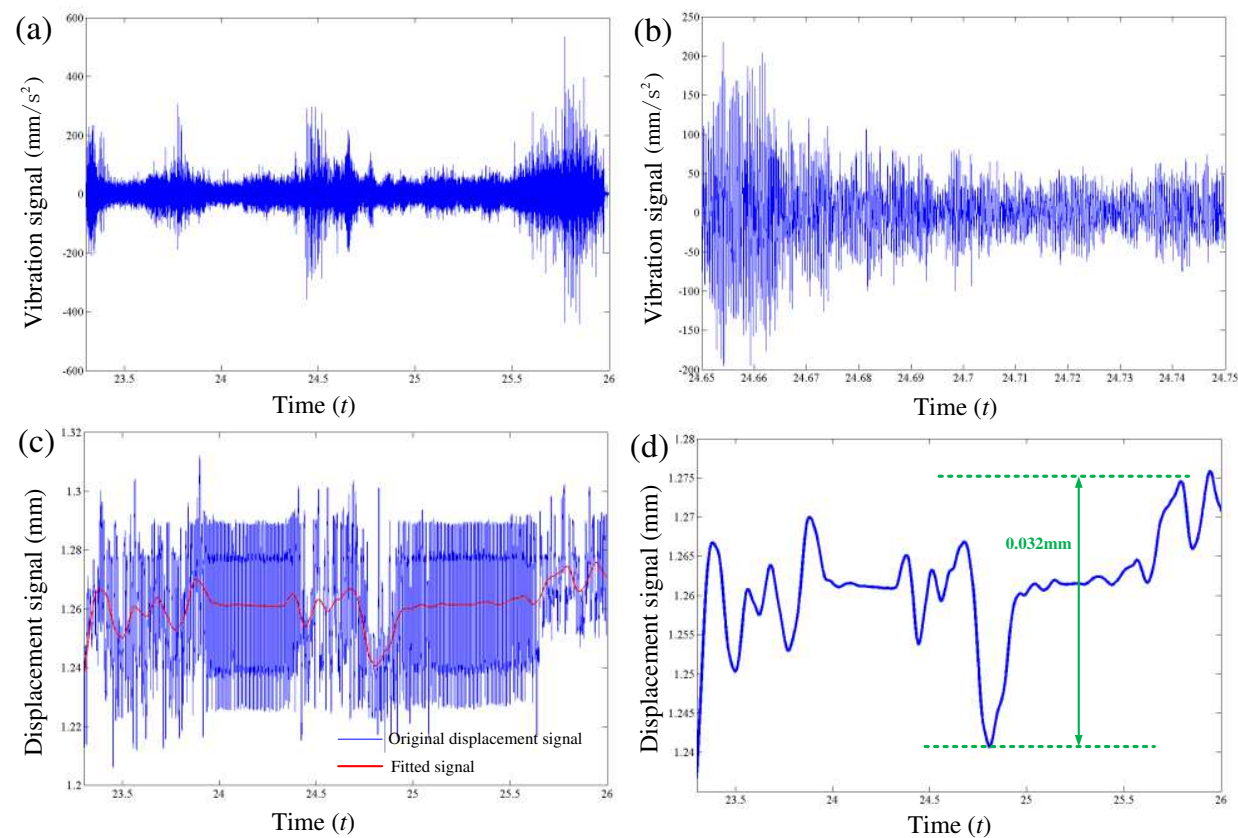

Fig. 14 Dynamic displacement response of blade-fixture system in the second process sequence (fixture 1\#). (a) Blade vibration during CNC machining process, (b) vibration value during a cycle of cutter force, (c) blade dynamic displacement response and (d) low-frequency dynamic displacement response of blade
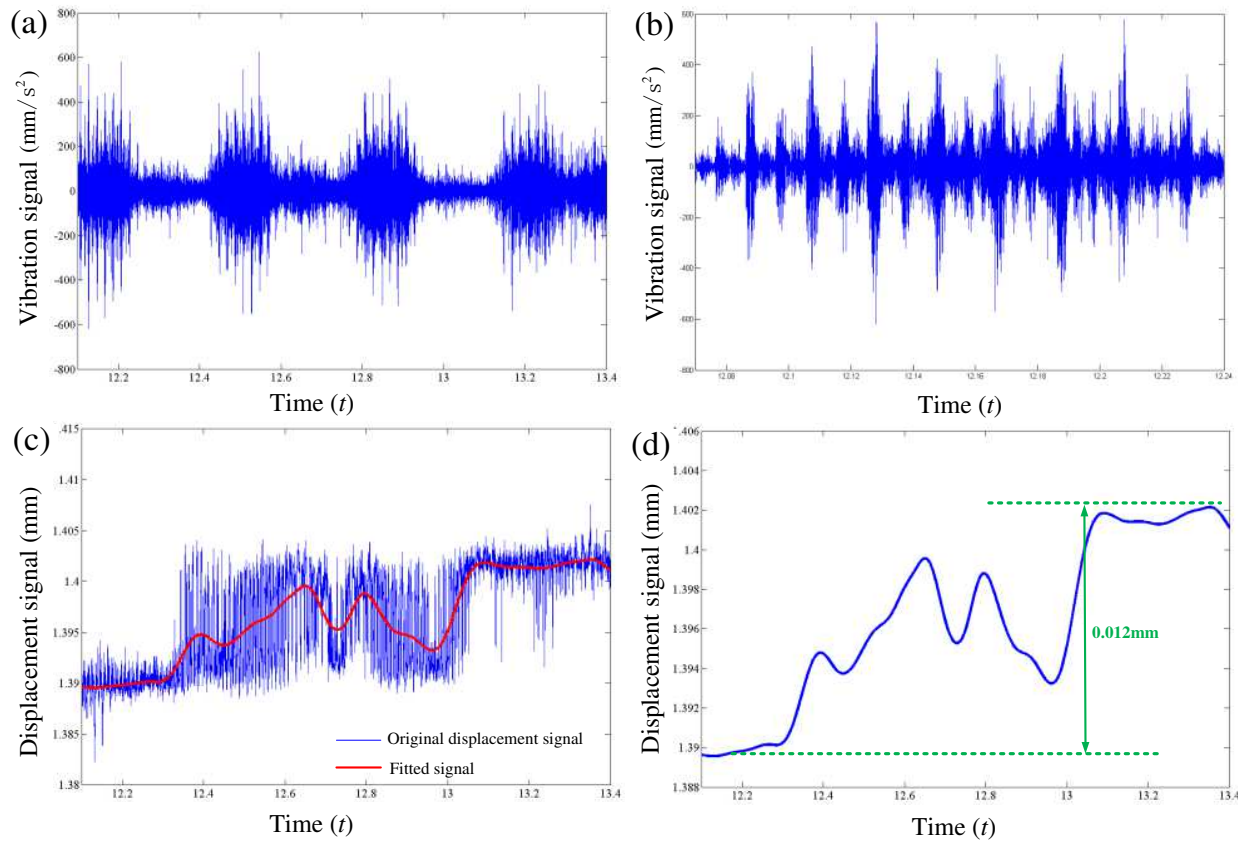

Fig. 15 Dynamic displacement response of blade-fixture system in the second process sequence (fixture 2\#). (a) Blade vibration during CNC machining process, (b) vibration value during a cycle of cutter force, (c) blade dynamic displacement response and (d) low-frequency 
dynamic displacement response of blade

Table 4 The processing parameters and the max dynamic displacement value of the second process sequence

\begin{tabular}{lcccc}
\hline Number & $\begin{array}{c}\text { Spindle } \\
\text { speed (rpm) }\end{array}$ & $\begin{array}{c}\text { Feed rate } \\
(\mathrm{mm} / \mathrm{min})\end{array}$ & $\begin{array}{c}\text { Cutting } \\
\text { depth }(\mathrm{mm})\end{array}$ & $\begin{array}{c}\text { The max dynamic } \\
\text { displacement value } \\
(\mathrm{mm})\end{array}$ \\
\hline 1 & 2000 & 1200 & 0.2 & 0.012 \\
2 & 3000 & 600 & 0.2 & 0.008 \\
3 & 3000 & 1000 & 0.2 & 0.013 \\
4 & 3000 & 1200 & 0.1 & 0.007 \\
5 & 3000 & 1200 & 0.2 & 0.012 \\
6 & 3000 & 1200 & 0.3 & 0.009 \\
7 & 3000 & 1200 & 0.4 & 0.015 \\
8 & 3000 & 1400 & 0.2 & 0.014 \\
9 & 4000 & 1200 & 0.2 & 0.014 \\
10 & 5000 & 1200 & 0.2 & 0.014 \\
\hline
\end{tabular}

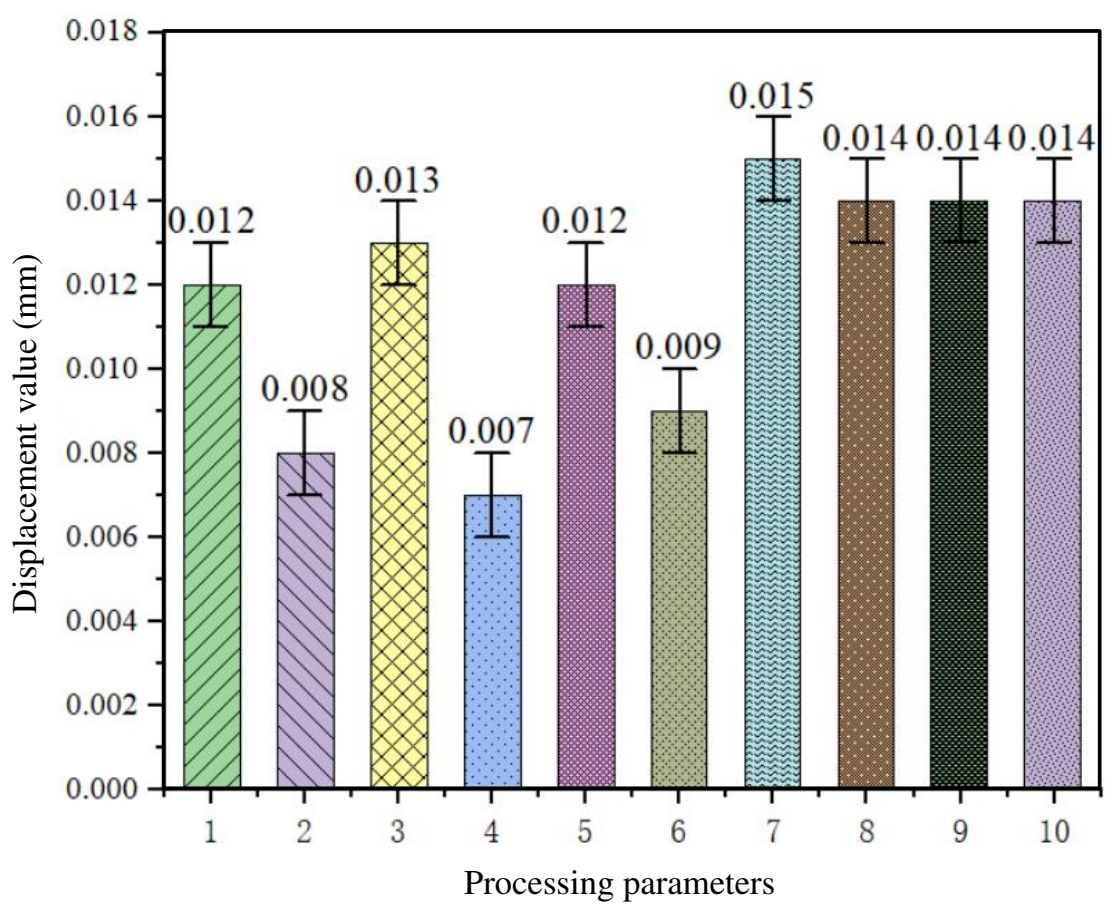

Fig. 16 The processing parameters and the max dynamic displacement value of the second process sequence 
In summary, the maximum dynamic response value of blade finishing process can be controlled within $0.007 \mathrm{~mm}$, and that of blade rough process can be controlled within $0.015 \mathrm{~mm}$ in the first and second process sequences. There are no weak stiffness links in the $\mathrm{CNC}$ machining process considering the first and second process sequence, which provide the stiffness prerequisite guarantee for the optimization of the whole process adaptive $\mathrm{CNC}$ machining process. The stiffness prerequisite guarantee combined with the adaptive $\mathrm{CNC}$ machining process optimization method can provide optimized solution for precision machining of near- net- shaped blade.

\subsection{Blade adaptive CNC machining process optimization}

Figure 17 shows the benchmark conversion during the near- net- shaped blade CNC machining process. The blade CNC machining process mainly consists of three processes. In the first process, the blade false boss is used as the positioning benchmark to machine the LTE of the blade. In the second process, the LTE which is obtained in the previous process and the section line of the blade body are used as the positioning benchmark to machine the blade tenon root and tip. In the third process, the blade tenon root obtained in the previous process is used as the benchmark to detect the position error and profile error of the blade section line of the blade processing. It can be seen that the process benchmark of the whole $\mathrm{CNC}$ machining process changes repeatedly, and the blade benchmark brings a lot of machining errors.
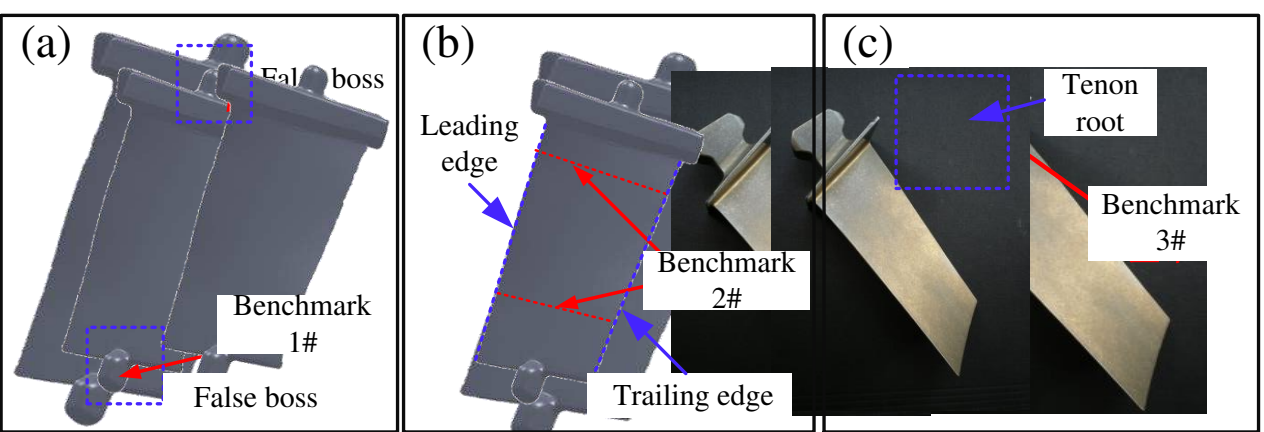

Fig. 17 Benchmark conversion between multiple processes in the processing of near- net- shaped blades. (a) The first processes procedure benchmark, (b) the second processes procedure benchmark and (c) the third processes procedure benchmark

Figure 18 shows the adaptive CNC machining process scheme which is based on the twice blade body on-machine measurement to achieve blade machining error control. Firstly, with 81 points of the blade body measured by on-machine measurement, 
the matching relationship between the blade body measurement value and the blade theoretical value is used to realize the blade tenon root position error control. Secondly, the cross-section line on the other side of the blade tenon root is measured to control the profile of the blade tenon root, and the blade body 81 points are on-machine measured to ensure the position of the blade tenon root relative to the blade body. In the above adaptive $\mathrm{CNC}$ machining process, the two blade body measurement processes are used to accurately adjust the position and posture of the blade to control the blade position error and profile error. The process of this adaptive $\mathrm{CNC}$ machining process is reduced by $50 \%$ compared with the blade low melting point alloy casting process. However, this adaptive CNC machining process is not the most efficient due to the introduction of two blade body measurement procedures. Based on this, the entire process of adaptive $\mathrm{CNC}$ machining process is optimized to reduce the measurement links and achieve the improvement of processing efficiency.
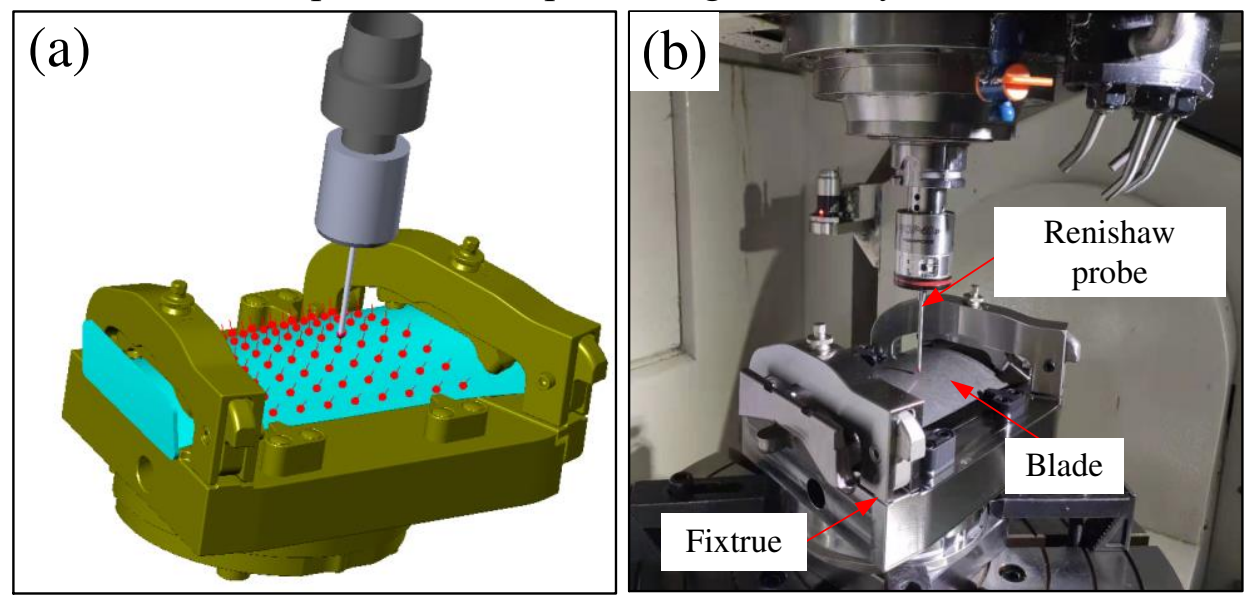

Fig. 18 Adaptive CNC machining process based on the twice blade body measurement. (a) Adaptive CNC machining process of blade body measurement and (b) on-machine measurement site

In fact, the machining process benchmarks in the blade $\mathrm{CNC}$ machining process will inevitably deviate due to large machining errors, and these machining errors between the two process procedures are accumulated in series. It is completely possible to combine the two process procedure benchmarks as a unified benchmark from the perspective of the machining process benchmarks. The process features for the second process procedure are machined after the first process procedure. In this way, the second process procedure feature is directly measured to reconstruct the adaptive CNC machining model to ensure the positioning error of the tenon root and the blade body. The main adaptive $\mathrm{CNC}$ machining measurement and model reconstruction focuses on the adaptive $\mathrm{CNC}$ machining process of the first process procedure, and the benchmark 
for the second process procedure is established through the convergence of the two process procedures. If the machining error flow of the entire process of the first and second process procedures is controlled, the coordinated control of all machining errors will be realized. The optimized specific machining process is shown in Figure 19.

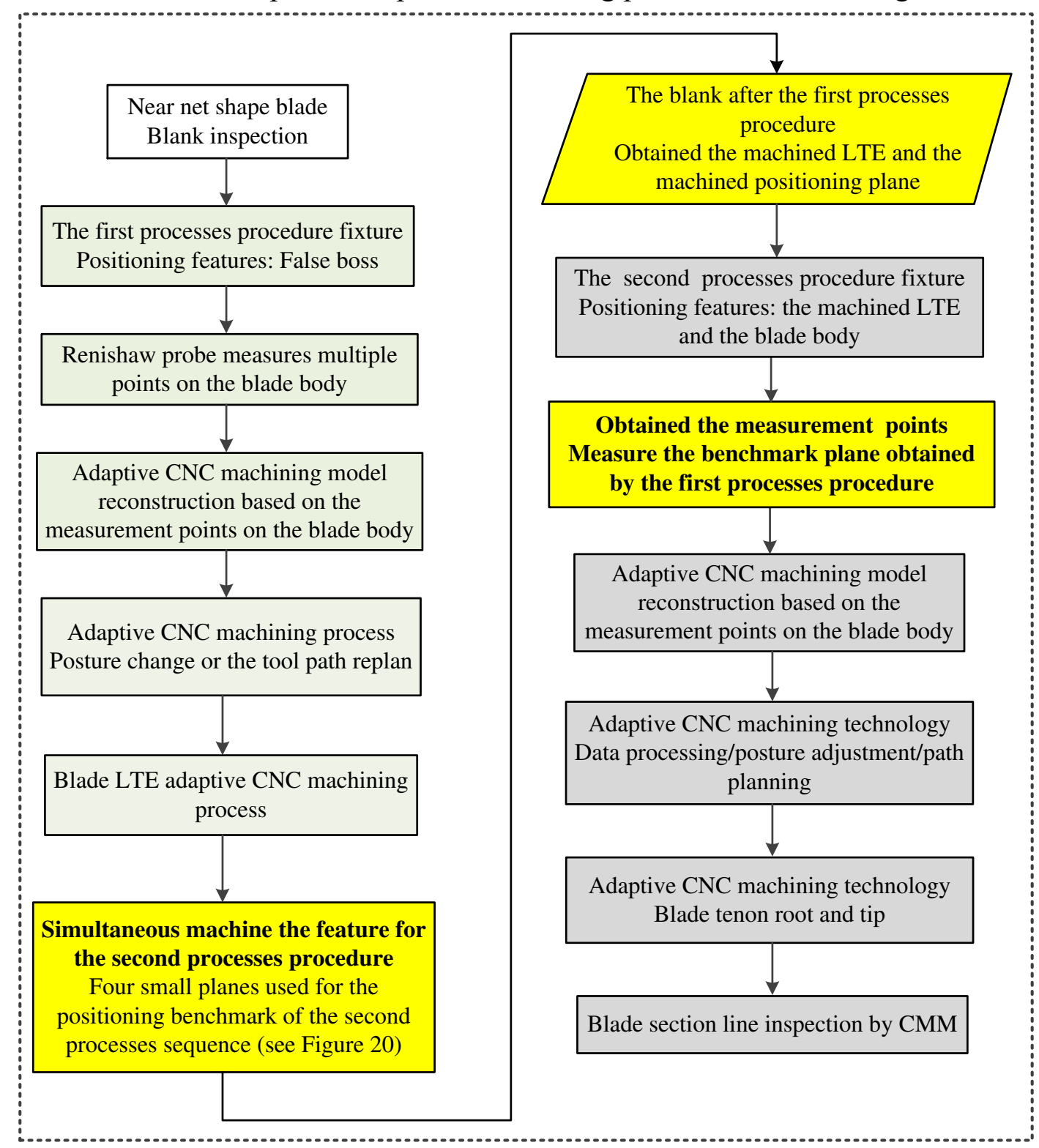

Fig. 19 The optimized specific machining process
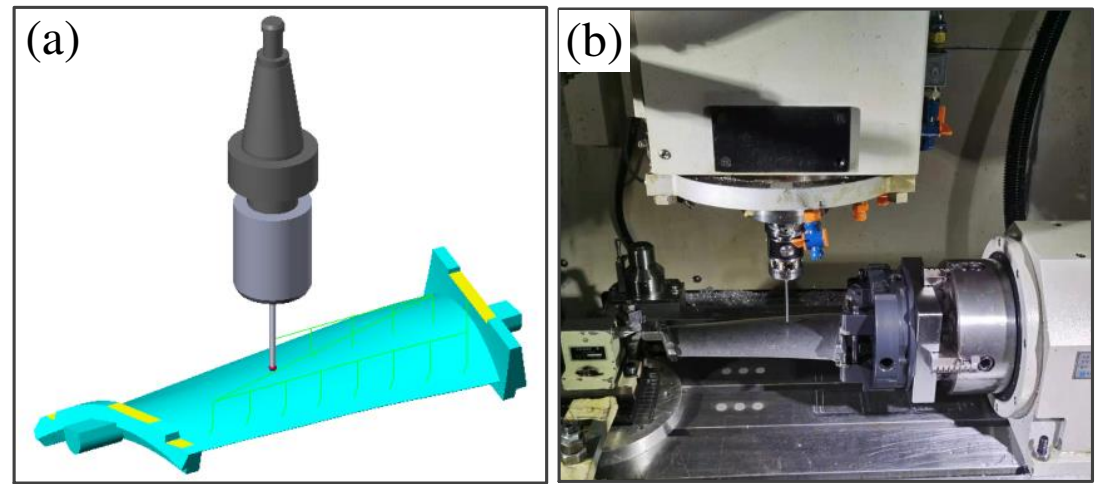
Fig. 20 The first process sequence adaptive $\mathrm{CNC}$ machining process blade measurement. (a) Measurement points and measurement path and (b) four-axis machine tool measurement process site

Figure 21 shows the first process sequence of the optimized adaptive CNC machining process, and the blade measurement model is obtained through the blade body data measurement. The measurement model and the theoretical model are registered to obtain the adaptive $\mathrm{CNC}$ machining process reconstruction model to ensure the position of the blade tenon root relative to the blade body.
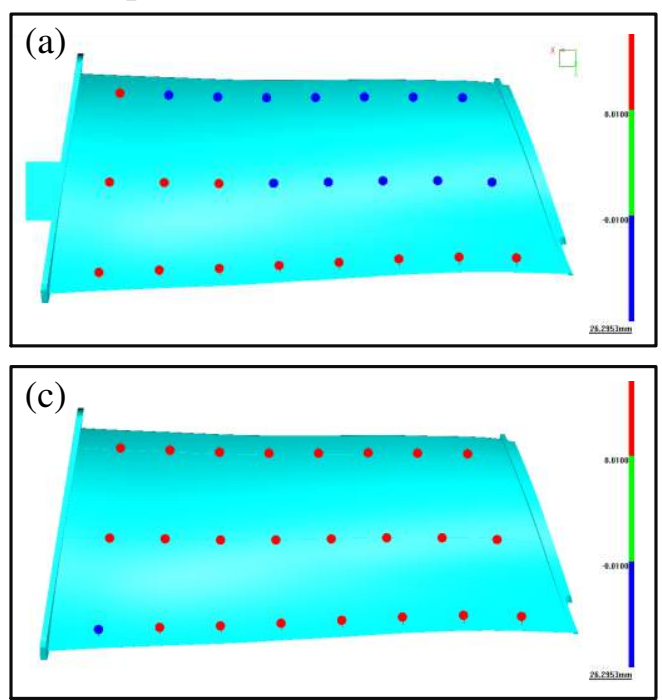
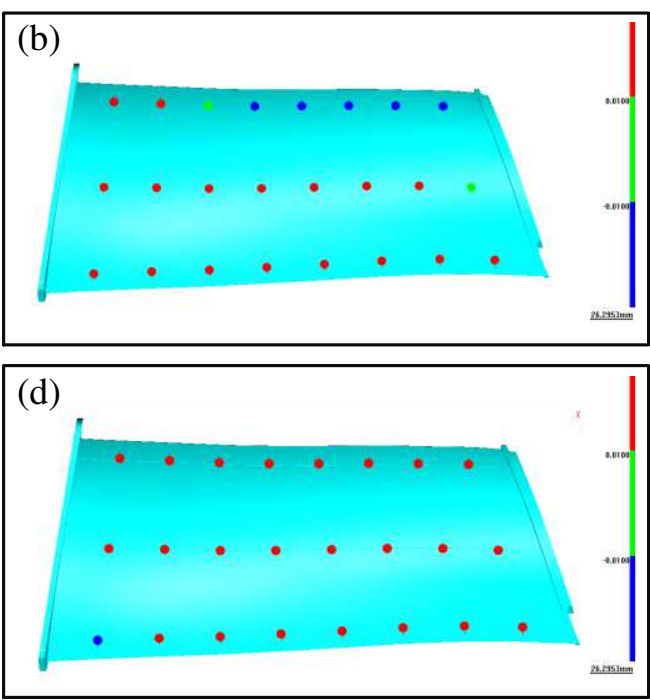

Fig. 21 Single-point deviation value of blade body measurement point during the first process sequence of the adaptive $\mathrm{CNC}$ machining process. (a) The initial state of blade in the fixture, (b) adaptively $\mathrm{CNC}$ machining regulate in the first stage, (c) adaptively $\mathrm{CNC}$ machining regulate in the second stage and (d) adaptively $\mathrm{CNC}$ machining regulate in the acceptable state process

Figure 21 is the single-point deviation value of blade body measurement point during the first process sequence of the adaptive CNC machining process. It can be seen from Figure 21(a) that some of the single-point deviation values of these 24 measurement points of the blade body are greater than $0 \mathrm{~mm}$, and some are less than 0 $\mathrm{mm}$ when the blade is initially installed on the fixture, and the specific numerical chart corresponds to Figure 22. This shows that the blade is not in an ideal position and attitude. The blade LTE and the benchmark facet for the second process sequence machined at this position will inevitably cause the uncontrollable machining position error of the blade tenon root relative to blade body. This is because that there is a geometric deviation of $0.008-0.05 \mathrm{~mm}$ in the blade profile size of the blade body. 
However, it can be determined that the error is all positive indicating that the blade has a positive margin value. Therefore, when some of the blade body measurement points are less than $0 \mathrm{~mm}$, it can be concluded that the blade is in an undesirable posture state at this time, and a subsequent adaptive regulation is required. In the same principle, there are still some single-point deviations greater than $0 \mathrm{~mm}$, and some are less than $0 \mathrm{~mm}$ in the first stage of adaptive regulation in Figure 21(b) showing that the blade is still in a non-ideal position at this time. The specific values are shown in Figure 22, which shows that the blade still needs subsequent adaptive regulation. In the same principle, there are still some single-point deviation values some of which are greater than $0 \mathrm{~mm}$, and some are less than $0 \mathrm{~mm}$ in the second stage of adaptive regulation (Figure 21(c)). It shows that the blade is still in a non-ideal position at this time, and the specific values are shown in Figure 22. The number of measurement points with a single point deviation value of less than $0 \mathrm{~mm}$ is reduced comparing to Figure 21(b) indicating that the adaptive $\mathrm{CNC}$ machining process at this time plays a certain role. However, it does not ensure that all the deviation values of the measurement points are greater than $0 \mathrm{~mm}$ indicating that the single point deviation value of the blade is not uniform. There is still a large deviation value, which shows that the blade still needs subsequent adaptive regulation. However, in Figure 21(d), the single-point deviation values of all measurement points are greater than $0 \mathrm{~mm}$ in the final stage of adaptive regulation, and the specific numerical values are shown in Figure 22, which shows that the single-point deviation values of the measurement points are all positive values and uniform distribution. That is, all measurement points of the blade body are evenly distributed on both sides of the theoretical model of the blade at this time indicating that the blade is in an ideal position. Based on the above analysis, the adaptive CNC machining process plays a significant role. The LTE and the benchmark facet for the second process sequence are machined in this state can ensure the position of the LTE and the benchmark facet for the second process sequence, and so as to provide guarantee for the benchmark transfer of the whole process with the first and second process sequences considered. 


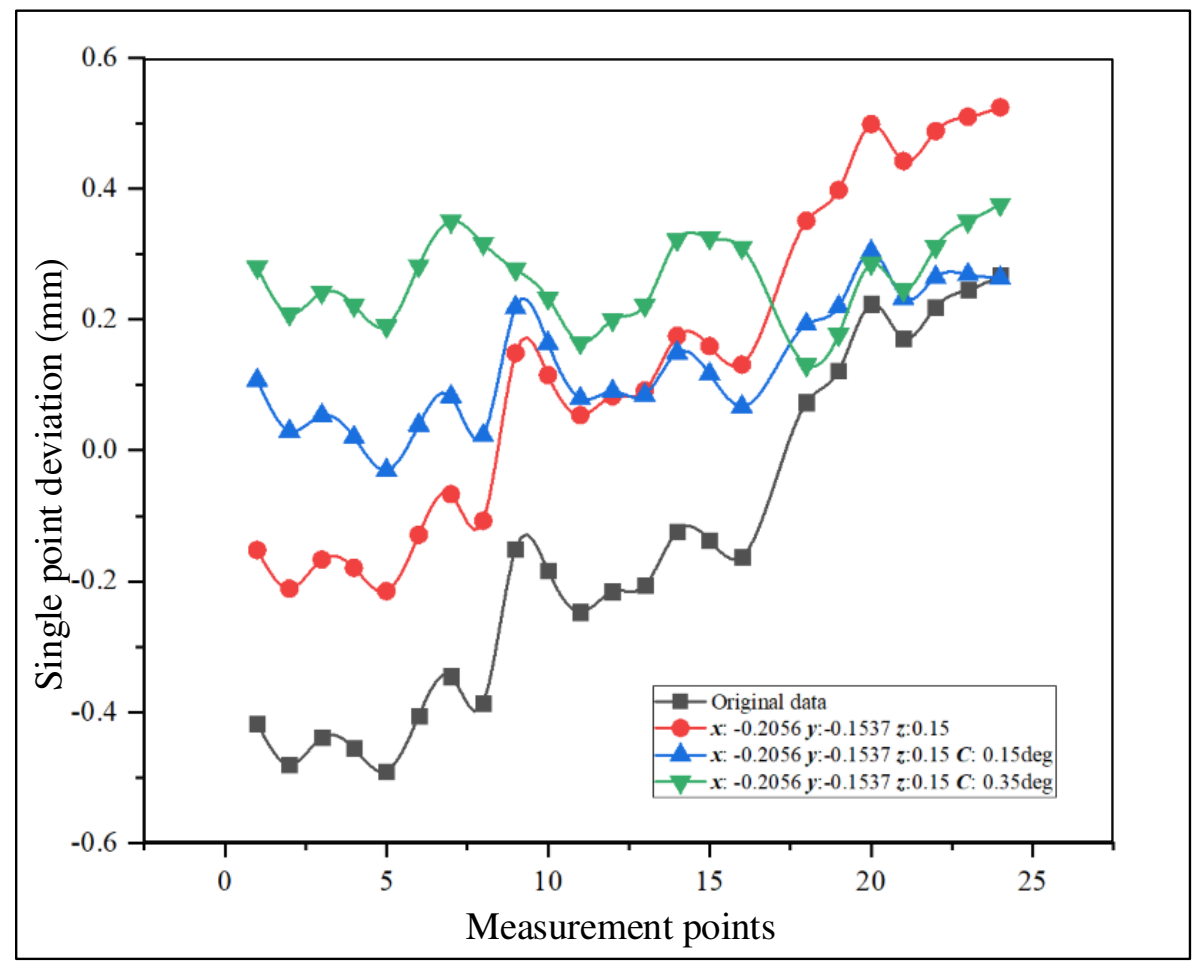

Fig. 22 Specific numerical chart of single-point deviation value of blade body measurement points during the first process sequence of the adaptive $\mathrm{CNC}$ machining process.

Figure 23 is the benchmark facet for the second process sequence measurement in the four-axis machine tool during the first process sequence of the blade adaptive CNC machining process. As shown in Figure 20, in the optimized specific machining process, the LTE of the blade and the benchmark facet for the second process sequence are machined in the first process sequence, and there are four benchmark facets in total as shown in Figure 23. After the benchmark facet is machined, the position state of the benchmark facet is measured based on the on-machine measurement state, and the position state of the blade benchmark facet at this time is recorded.
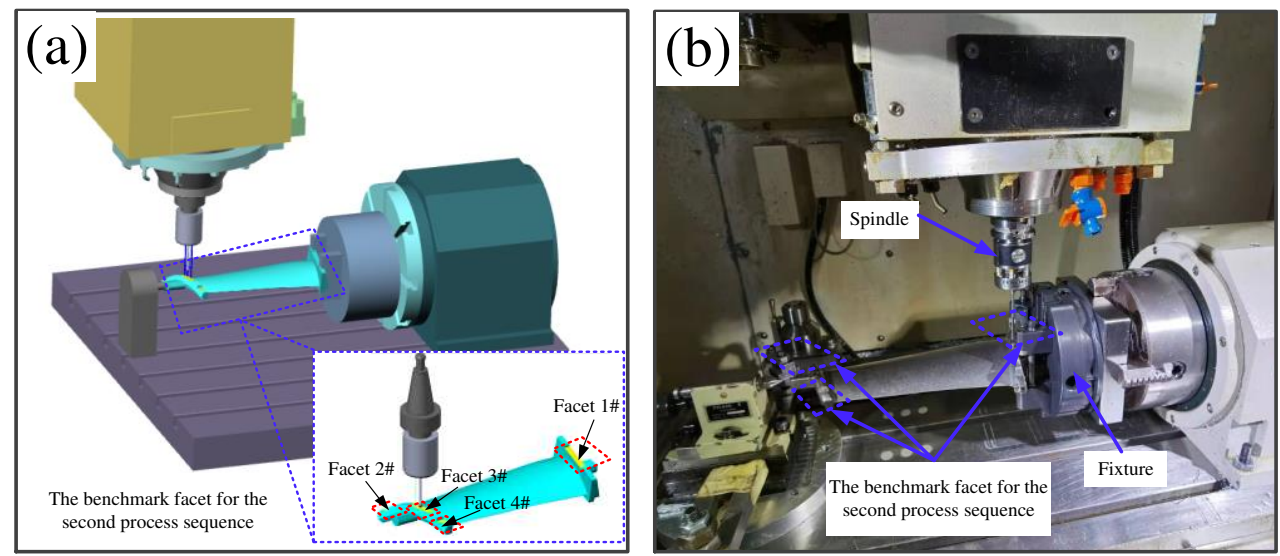

Fig. 23 The benchmark facet for the second process sequence 
measurement in the four-axis machine tool during the first process sequence of the blade adaptive CNC machining process.

The machined blade LTE and the benchmark facet for the second process sequence measurement will be obtained after the first process sequence is completed, and then the second process sequence will be performed. Figure 23 is the measurement link of the blade second process sequence of adaptive CNC machining process, and this process is mainly to machine the blade tenon root and tip. In the optimized process, only the benchmark facets that machined in the first process sequence for the second process sequence measurement are needed to be measured. The position status of the benchmark facets 1\#, 2\#, 3\# and 4\# (see Figure 23) on the four- axis machine tool (the first process sequence) and five- axis machine tool (the second process sequence) are respectively obtained. Therefore, the same single-point deviation value is obtained under the two fixture installation positions, and the whole process multi-process machining error data flow control is realized.
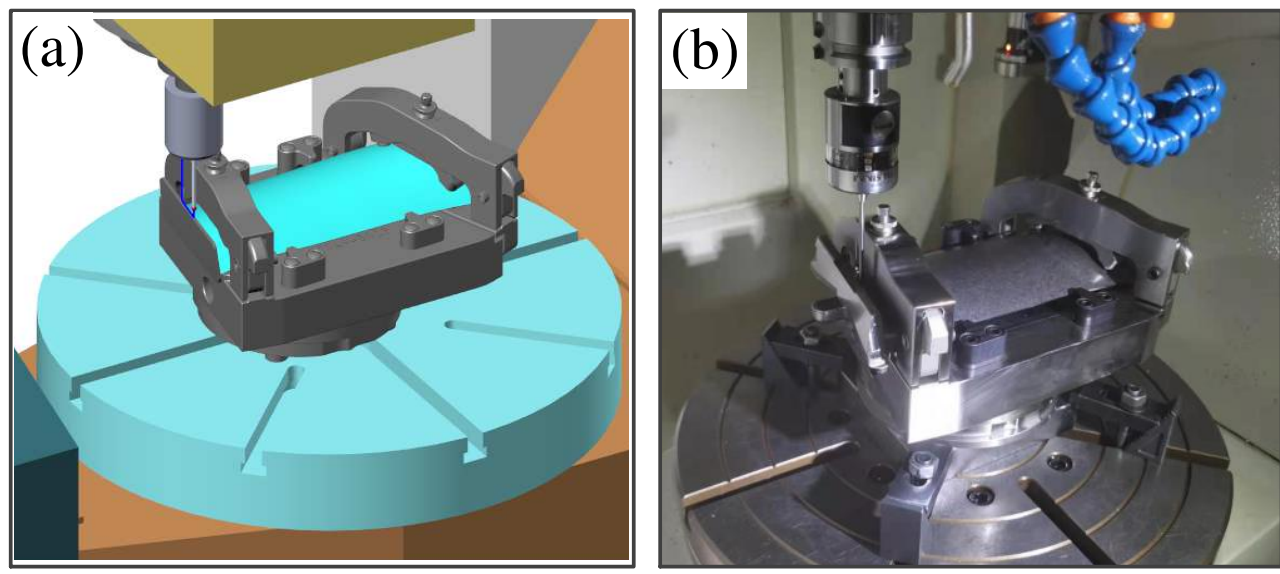

Fig. 24 The benchmark facets are measured in the five-axis machine tool during the second process sequence of the blade adaptive $\mathrm{CNC}$ machining process.

Table 5 shows the distribution of the multi-process collaborative benchmark conversion margin. The corresponding benchmark facet is shown in Figure 25, and the specific single-point deviation value is shown in Figure 26. The benchmark facets for the second process sequence measurement after roughing machining, semi-finishing and finishing machining in the first processing sequence is obtained by $\mathrm{CNC}$ machining process in a four-axis machine tool (see Figure 23), and this benchmark facets are four small facets, and the flatness and position of these benchmark facets can be ensured by the first process sequence of the blade adaptive $\mathrm{CNC}$ machining process.

Table 5 Blade benchmark facet margin value in the first process sequence 
and the second process sequence

\begin{tabular}{lllllll}
\hline \multirow{2}{*}{$\begin{array}{l}\text { Benchmark } \\
\text { facet }\end{array}$} & Measurem & \multicolumn{3}{c}{ The first process sequence } & & \multicolumn{2}{l}{$\begin{array}{l}\text { The second } \\
\text { process sequence }\end{array}$} \\
\cline { 3 - 7 } & ent point & $\begin{array}{l}\text { Under initial } \\
\text { installation }\end{array}$ & $\begin{array}{l}\text { Roughing } \\
\text { milling }\end{array}$ & $\begin{array}{l}\text { Semi- } \\
\text { finishing } \\
\text { milling }\end{array}$ & $\begin{array}{l}\text { Finishing } \\
\text { milling }\end{array}$ & $\begin{array}{l}\text { After adaptive } \\
\text { regulation }\end{array}$ \\
\hline Facet 1\# & 1 & 0.8423 & 0.8437 & 0.8443 & 0.8497 & 0.8502 \\
& 2 & 0.8423 & 0.8435 & 0.8439 & 0.8497 & 0.8476 \\
& 3 & 0.8417 & 0.8435 & 0.8437 & 0.8487 & 0.8471 \\
Facet 2\# & 4 & 0.4487 & 0.2895 & 0.2903 & 0.2599 & 0.2836 \\
& 5 & 0.3707 & 0.3218 & 0.3224 & 0.2596 & 0.2785 \\
& 6 & 0.5237 & 0.5243 & 0.4037 & 0.2595 & 0.2793 \\
Facet 3\# & 7 & 1.1189 & 1.1207 & 1.1215 & 1.1269 & 1.1242 \\
& 8 & 1.1188 & 1.1178 & 1.1184 & 1.1236 & 1.1218 \\
& 9 & 1.119 & 1.1197 & 1.1201 & 1.1255 & 1.1266 \\
\hline
\end{tabular}

It can be seen from Figure 25 and Figure 26 that the single-point deviation of the blade benchmark facet in the second fixture installation state under the five-axis machine tool which is the second process sequence is consistent with that under the first sequence fixture installation state after two sequences adaptive CNC machining process in five-axis machine tool on-machine measurement and adjustment regulation. The benchmarks transition from the first process sequence to the second process sequence is realized, and the position error and profile error of the blade tenon root relative to the blade body can be controlled while the rigidity of the second process sequence fixture is ensured. 

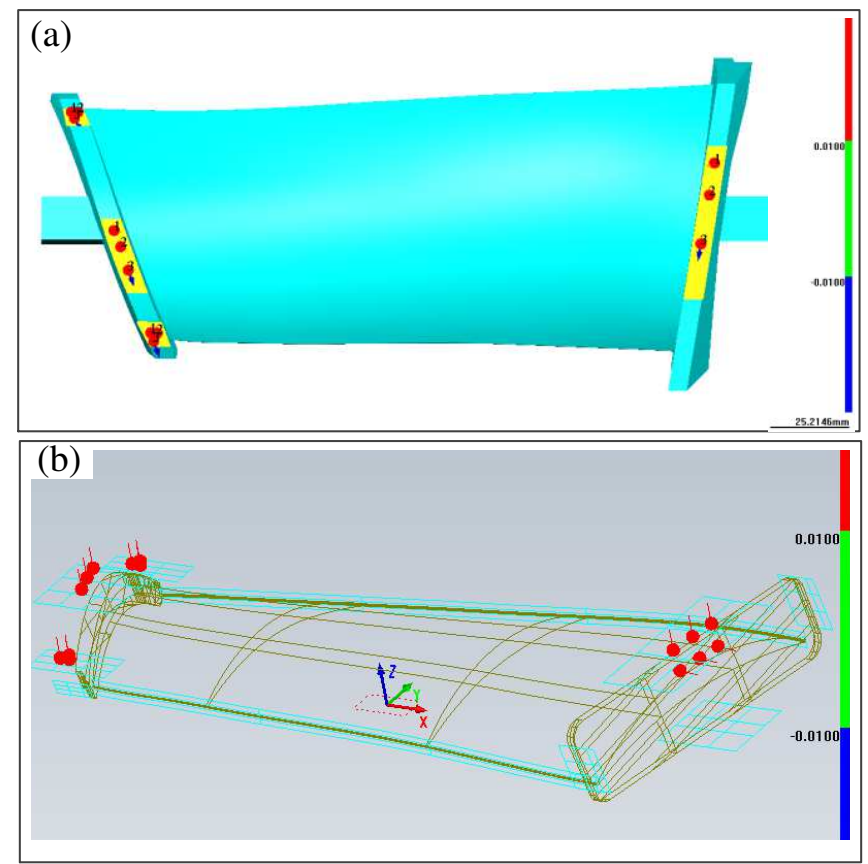

Fig. 25 Blade benchmark facet margin value. (a) In the first process sequence and (b) in the second process sequence

The above process sequences realize the cohesion of two fixture benchmarks for the two processes. As the first process sequence completed on the four-axis machine tool, the adaptive CNC machining process scheme can be simplified with the redundancy of the blade body measurement in the second process eliminated. The measurement time is saved to improve the processing efficiency under the premise that the position error and profile error of the tenon root relative to the blade body are ensured.

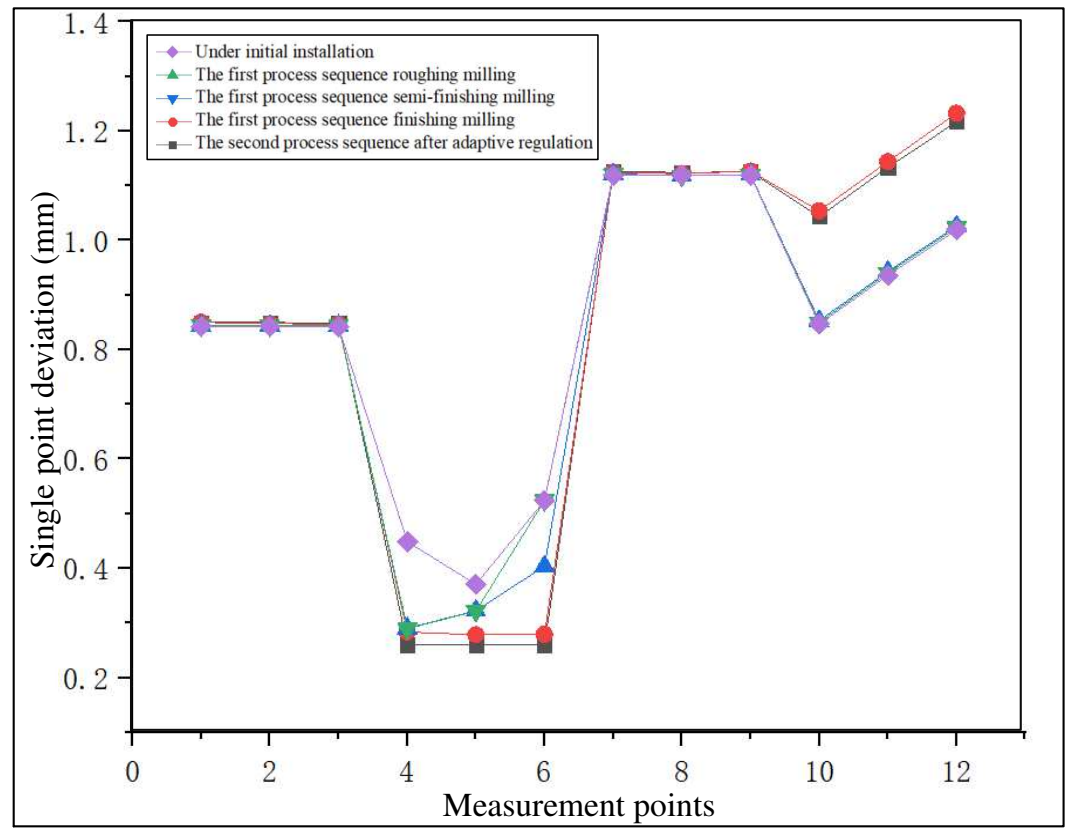


Fig. 26 Blade benchmark facets margin value change trend graph

\subsection{Machining accuracy analysis of the optimized adaptive CNC machining process}

Figure 27 is the single point deviation value of the blade body after the two process sequences of adaptive $\mathrm{CNC}$ machining process, it can be seen that the single-point deviation values of the blade body are uniformly distributed, and all the single-point deviation values are positive, and there are no measurement points with a deviation value less than $0 \mathrm{~mm}$. This is because that the blade body itself has a positive margin, and the positive margin value is about $0.008-0.05 \mathrm{~mm}$, and these deviation values still exist due to the blade body has not undergone subsequent CNC machining process. If these single-point deviation values are all greater than $0 \mathrm{~mm}$, and these single-point deviation values are evenly distributed, it can be indicated that the position of the blade does not deviate during the blade tenon root $\mathrm{CNC}$ machining processing, explaining that the stiffness of the blade- fixture system is sufficient, which is consistent with the previous analysis of natural frequency and dynamic displacement response analysis.

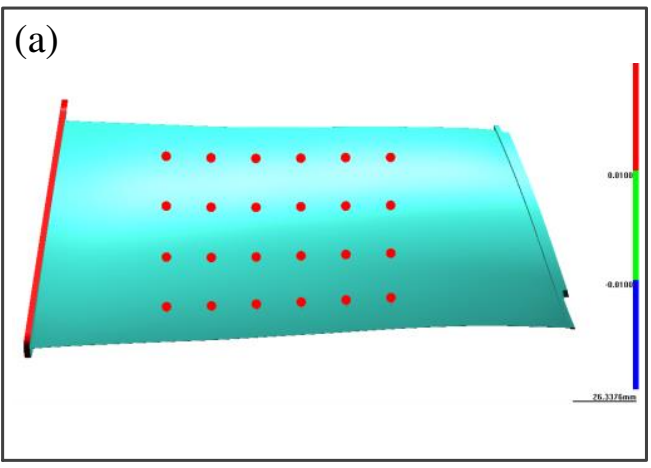

Fig. 27 Single point deviation of blade body, (a) blade body measurement points, (b) single-point deviation distribution value of blade body.

Figure 28 is the single-point deviation value of the blade tenon root and tip after the two process sequences. It can be seen that the deviation values of all the measurement points are within the range of -0.007 to $0.007 \mathrm{~mm}$, which shows that not only the machined surface profile meets the range of the machining error band, but also the position errors of the blade tenon root and tip meet the machining error range through the coordinated machining error data flow control of the two process sequences in the adaptive CNC machining process. The stiffness of the blade- fixture system is sufficient, and the proposed adaptive $\mathrm{CNC}$ machining process optimization based on 
machining error data flow control is feasible.
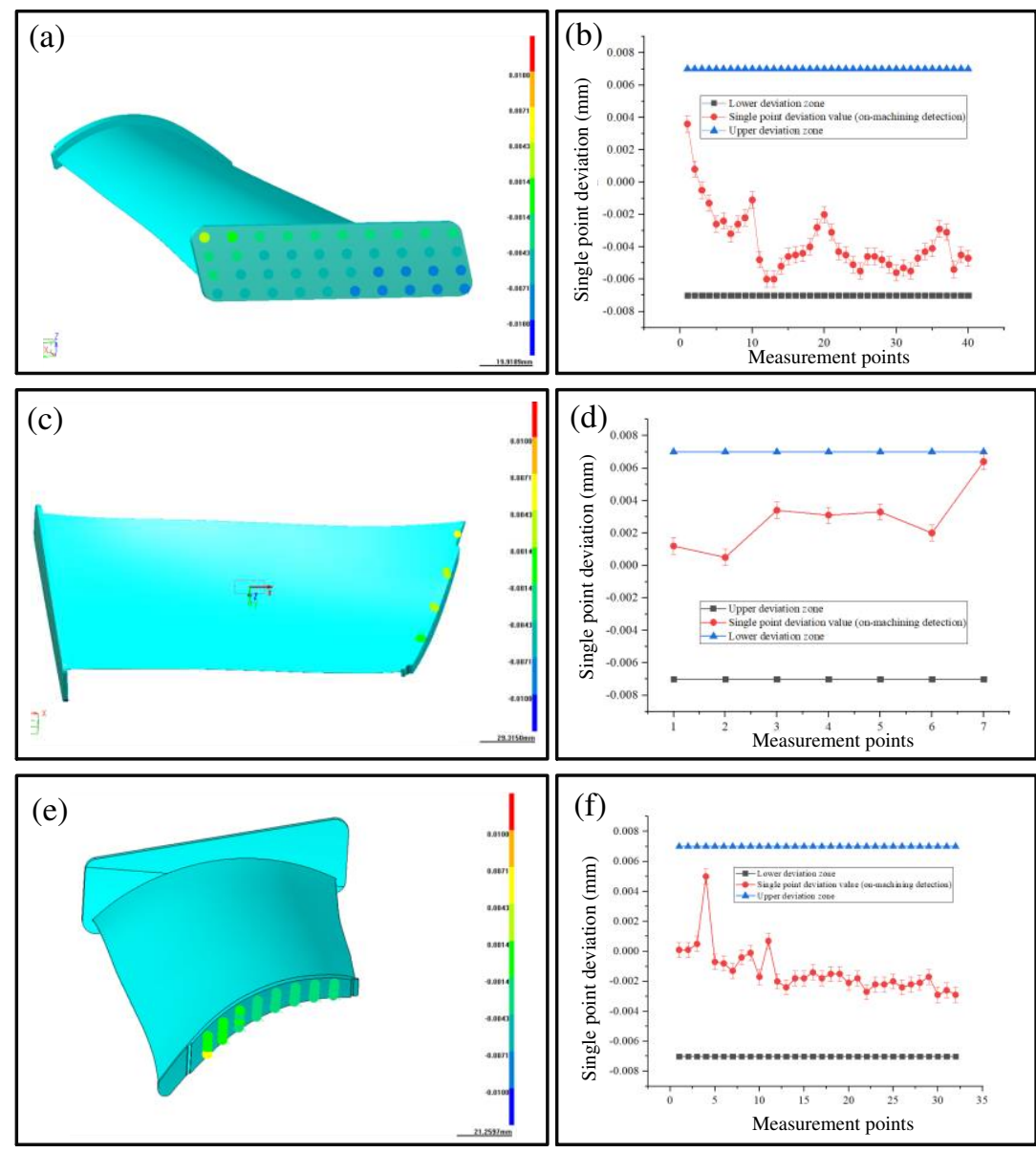

Fig. 28 Single point deviation of blade tenon root and tip. (a) Blade tenon root measurement points, (b) single-point deviation distribution value of blade tenon root, (c) blade tip measurement points, (d) singlepoint deviation distribution value of blade tip, (e) blade tip side measurement points and (f) single-point deviation distribution value of blade tip side

From the perspective of machining efficiency, the traditional low melting point alloy casting process has $15 \mathrm{CNC}$ machining sequences (see Figure 2), while the optimized adaptive $\mathrm{CNC}$ machining process has only two $\mathrm{CNC}$ machining sequences (see Figure 20). The number of CNC machining sequences is reduced by $87 \%$. Compared with the twice on-machine measurement of the blade body profile points respectively for blade LET and the tenon root CNC machining process, the optimized adaptive $\mathrm{CNC}$ machining process only needs to complete the on-machine measurement of blade body and machining error transmission benchmark facets. The number of measurement points on the benchmark facets are less than the measurement points on 
the blade body, and the number of measurement points is reduced by $50 \%$, which improves the efficiency by $50 \%$.

The process chain of the optimized adaptive $\mathrm{CNC}$ machining process based on machining error data flow control is reduced by $87 \%$ compared with the low melting point alloy pouring process, and 50\% compared with adaptive $\mathrm{CNC}$ machining process of the twice on-machine measurement of the blade body. The reduction of blade process chain is beneficial to improve blade CNC machining efficiency.

In summary, the optimized adaptive $\mathrm{CNC}$ machining process based on machining error data flow control has excellent performance in machining accuracy and efficiency.

\section{Conclusion}

In this study, the machining error data flow and dynamic displacement response of the multi- process adaptive CNC machining process of near- net- shaped blade were investigated by theoretical and experimental analysis, and the results can be summarized as follows:

1) The dynamic displacement response of the multi-process adaptive CNC machining process is controlled within $0.007 \mathrm{~mm}$, and the sufficient stiffness of bladefixture system provides a prerequisite guarantee for adaptive $\mathrm{CNC}$ machining process optimization.

2) The optimized adaptive $\mathrm{CNC}$ machining process can realize the multi-process machining error control and high-precision manufacturing of near- net- shaped blade based on the multi-process data flow transmission and control with sufficient stiffness of the multi-process blade- fixture system. The coordinated control of the two processing procedures achieves the blade tenon root position and contouring error control.

3) The process chain of the optimized adaptive CNC machining process based on machining error data flow control is reduced by $87 \%$ compared with the low melting point alloy pouring process and 50\% compared with adaptive CNC machining process of the twice on-machine measurement of the blade body. The reduction of blade process chain is beneficial to improve blade CNC machining efficiency.

However, the proposed adaptive CNC machining process is based on the geometric adaptive processing technology, and the improvement of processing accuracy can be achieved under the premise of the sufficient stiffness of the bladefixture system. How to achieve high-precision adaptive $\mathrm{CNC}$ machining process for the 
weak rigid process system will be the future research.

\section{Authors' contributions}

Dongbo Wu: experiment, data analysis, original draft writing

Hongru Lv: experiment and writing

Hui Wang: methodology, formal analysis, writing — review and editing

Jie Yu: experiment

\section{Funding}

This research was supported in part by Xi'an Aero-Engine (Group) Ltd. This research is supported in part by Project on the Integration of Industry, Education and Research of Jet Engine Corporation of China (HFZL2020CXY020).

\section{Data availability Not applicable}

\section{Compliance with ethical standards}

Ethical approval Not applicable

Consent to participate Not applicable

Consent to publish Not applicable

Code availability Not applicable

Competing interests The authors declare that they have no competing interests

\section{References}

1. Dongbo $\mathrm{Wu}$, Hui Wang\#, Jie Yu. Kaiyao Zhang, Machining fixture for adaptive CNC processing technology of near-net-shaped jet engine blade [J]. Chinese Journal of Aeronautics. 2020; 33, 1311- 1328.

2. Dongbo Wu, Hui Wang \#, Kaiyao Zhang, Bing zhao. Research on adaptive CNC machining arithmetic and process for near-net-shaped jet engine blade [J]. Journal of Intelligent Manufacturing 2020; 31, 717- 744.

3. HU S J. Stream of Variation theory for automotive body assembly[J]. Annals of the CIRP, 1997, 46(1): 1-6.

4. Ceglarek D, SHI J, WU S M. A Knowledge-based diagnosis approach for the launch of the auto-body assembly process[J]. ASME Journal of Engineer for Industry, 1994, 116(4): 491-499. 
5. Ceglarek D, SHI J. Fixture failure diagnosis for auto-body assembly using pattern recognition[J]. Journal of Engineering for Industry, 1996, 118: 55-66.

6. Walid Ghiea, Luc Laperriere, Alain Desrochers, Statistical tolerance analysis using the unified Jacobian-Torsor model, International Journal of Production Research, 2010, 48(15): 4609-4630.

7. Yan Rong, Chen Wei, Peng Fangyu, Lin Sen, Li Bin, Closed-chain stiffness field modeling and stiffness performance analysis of multi-axis machining system $[\mathrm{J}]$. Journal of Mechanical Engineering, 2012; 48 (1), 176-184.

8. Mantripragada Ramakrishna, Whitney Dani el E. Modeling and controlling variation propagation in mechanical assemblies using state transition models[J]. IEEE, Transactions on Robotic and Automation, 1999, 15(1): 124-140.

9. Jiayuan He, Yan Wang, Nabil Gindy. Pre-tensioning fixture development for machining of thin-walled components, Advanced Materials Research, 2011, (314316): 319-326.

10. James N. Asante, A combined contact elasticity and finite element-based model for contact load and pressure distribution calculation in a frictional workpiece-fixture system, International Journal of Advanced Manufacturing Technology, 2008, 39: 578-588

11. Y. Wang, X. Chen, N. Gindy, Surface error decomposition for fixture development, International Journal of Advanced Manufacturing Technology, 2007, 31: 948-956

12. Y. Wang, X. Chen, N. Gindy, J. Xie. Elastic deformation of a fixture and turbine blades system based on finite element analysis, International Journal of Advanced Manufacturing Technology, 2008, 36: 296-304

13. K.P. Padmanaban, K.P. Arulshri, G. Prabhakaran, Machining fixture layout design using ant colony algorithm based continuous optimization method, International Journal of Advanced Manufacturing Technology, 2009, 45: 922-934

14. He Ning, Wang Zhigang, Jiang Chengyu, Zhang Bing, Finite element method analysis and control stratagem for machining deformation of thin-walled components, Journal of Materials Processing Technology, Volume 139, Issues 1-3, 20 August 2003, Pages 332-336

15. Weifang Chen, Lijun Ni, Jianbin Xue, Deformation control through fixture layout design and clamping force optimization, International Journal of Advanced Manufacturing Technology, 2008, 38: 860-867

16. E. Budak, Analytical models for high performance milling. Part I: Cutting forces, 
structural deformations and tolerance integrity, International Journal of Machine Tools \& Manufacture, 2006, (46): 1478-1488

17. Baohai Wu, Ming Luo, and Dinghua Zhang, An efficient approach for identifying stable lobes with discretization method, Advances in Mechanical Engineering, 2013, doi:10.1155/2013/682684.

18. Ge Gao, Baohai Wu, Dinghua Zhang, Ming Luo. Mechanistic identification of cutting force coefficient in bull-nose milling process. Chinese Journal of Aeronautics, 2013, 26(3): 823-830.

19. Yilong Liu, Dinghua Zhang, Baohai Wu. An efficient full-discretization method for prediction of milling stability. International Journal of Machine Tools and Manufacture, 2012, 63: 44-48.

20. Guijian Xiao*, Yun huang, Ying Liu, Quan Li,Wentao Dai. Analysis of Vibration on Weakly Rigid Contact Flutter in Belt Grinding of Blisk Blade[J]. Journal of Engineering Manufacture, 2018.

21. Dongbo Wu, Bing Zhao, Hui Wang, Kaiyao Zhang, Jie Yu. Investigate on computer-aided fixture design and evaluation algorithm for near-net-shaped jet engine blades. Journal of Manufacturing Processes, 54 (2020) 393-412. 